NASA/TM-1998-208498

\title{
Launch Vehicle Performance With Solid Particle Feed Systems for Atomic Propellants
}

Bryan Palaszewski

Lewis Research Center, Cleveland, Ohio

Prepared for the

34th Joint Propulsion Conference and Exhibit cosponsored by AIAA, ASME, SAE, and ASEE

Cleveland, Ohio, July 13-15, 1998

National Aeronautics and Space Administration

Lewis Research Center 
Available from

NASA Center for Aerospace Information 7121 Standard Drive

Hanover, MD 21076

Price Code: A03
National Technical Information Service 5287 Port Royal Road Springfield, VA 22100 Price Code: A03 


\title{
LAUNCH VEHICLE PERFORMANCE WITH SOLID PARTICLE FEED SYSTEMS FOR ATOMIC PROPELLANTS
}

\author{
Bryan Palaszewski* \\ National Aeronautics and Space Administration \\ Lewis Research Center \\ Cleveland, Ohio 44135
}

\begin{abstract}
SUMMARY
An analysis of launch vehicle Gross Liftoff Weight (GLOW) using high energy density atomic propellants with solid particle feed systems was conducted. The analyses covered several propellant combinations, including atoms of aluminum (Al), boron (B), carbon (C), and hydrogen $(\mathrm{H})$ stored in a solid cryogenic particle, with a cryogenic liquid as the carrier fluid. Several different weight percents $(w t \%)$ for the liquid carrier were investigated and the gross lift off weight (GLOW) of the vehicles using the solid particle feed systems were compared with a conventional $\mathrm{O}_{2} / \mathrm{H}_{2}$ propellant vehicle. The potential benefits and effects of feed systems using solid particles in a liquid cryogenic fluid are discussed.
\end{abstract}

\section{NOMENCLATURE}

A fixed mass scaling parameter, $\mathrm{kg}$
Al aluminum
B boron
B propellant dependent mass scaling parameter, $\mathrm{kg} / \mathrm{kg} \mathrm{Mp}$
C carbon
GLOW gross lift off weight
H atomic hydrogen
$\mathrm{He}$ helium
$\mathrm{H}_{2} \quad$ molecular hydrogen
Isp specific impulse, $s$
Mp propellant mass, $\mathrm{kg}$
NLS National Launch System
O/F oxidizer to fuel ratio, or mixture ratio
$\mathrm{O}_{2} \quad$ oxygen
wt $\% \quad$ weight percent

* AIAA Associate Fellow, Leader, NASA Advanced Fuels. 


\section{INTRODUCTION}

New technologies in atom isolation and the physics of material manipulation have led to the discovery and synthesis of materials that can be used as rocket propellants (Refs. 1 throu; 25 ). Solid cryogenic propellants storing atoms of Al, B, C, and $\mathrm{H}$, or other atomic additives, require a unique propulsion system design where the fuels are stored at liquid helium $(\mathrm{He})$ temperatures during ground handling and $\mathrm{flight}$. Feeding atomic propellants from a propellant tank through a feed system to a rocket engine will be a formidable challenge.

There are very extensive potential benefits for using atomic propeliants. Figure 1 shows the GLOW reductions with atomic hydrogen as a launch vehicle propellant for several atom loadings. With atomic hydrogen at an Isp value of 750 seconds, the GLOW can be reduced by $44 \%$ over the $\mathrm{O}_{2} / \mathrm{H}_{2}$ baseline case. The baseline case is the National Launch System (NLS) with a specific impulse (Isp) of 430 ser onds (Ref. 1). The 750 second atomic H Isp performance level requires a 15 - $w t \%$ of atomic hydrogen stored in soli.t $\mathrm{H}_{2}$. The reduction of the GLOW would result in a significant reduction of the cost of space launch, simplificati on of the ground support equipment and reduction in the investment in launch facilities.

This paper provides analyses of the rocket engine performance for several atomic propellants, and shows their effect on the GLOW of an Earth to Orbit rocket transportation vehicle. Several concepts for the formation, storage, and transport (i.e., feed systems) for atomic propellants are discussed. Also, analyses of the effects of using solid particle feed systems, and the challenges that must be overcome are presented.

\section{WHY HEDM PROPELLAN IS?}

The overarching vision for HEDM is to create a propellant combination that has at least the performance of $\mathrm{O}_{2} / \mathrm{H}_{2}$ (typical of the Space Shuttle, which delivers a specific impulse of 452 seconds, in vacuum) but with a higher overall propellant density. The goal is to reduce the vehicle GLOW, simplify vehicle ground operations, and ultimately reduce the cost of space access. Atomic propellants can theoretically offer an extremely high specific impulse over $\mathrm{O}_{2} / \mathrm{H}_{2}$ propellants. The high-energy atomic propellant must be formulated very meticulously because they do not occur readily in nature. (Ref. 12, Collins). The atoms in the propellant must be stored in a stabilizing medium, such as a cryogenic solid, so as to inhibit or delay their recombination into molecules. Atomic propellants theoretically deliver very high specific impulse as the atoms recombine, release large amounts of energy, and heat the surrounding medium that is used to stabilize the atoms. Using these propellants is more complex than traditional propellants because of their unique chemistry and atomic interactions. Vext generation RLV propulsion systems could perhaps use these propellants consisting of atoms in frozen hydrc gen particles, within a cryogenic liquid carrier, such as helium (Ref. 10).

\section{VEHICLE DESIGNS AND FEED SYSTEMS}

Calculations of rocket engine performance conducted in the past (Ref. 1 and 11) have considered the atomic hydrogen and other atoms that are stabilized in a solid cryogenic mater al, such as hydrogen. This solid, however, is not easily fed though a conventional feed system. Previous propulsion studies have considered either a monolithic solid containing the atoms, or a segmented solid, much like the concep: of a throttleable or controllable solid rocket motor, with preprogrammed pulse elements, each separated by an inhit itor layer. While this may be a viable approach is some cases, the potential for the atoms remaining in a cryogenic atomic state is questionable. As the grain is exposed to the combustion environment, it's temperature goes up quickly, and the ability of the remaining propellant to remain in the atomic state drops dramatically. Isolation of the remaining propellant is needed to have the propellant remain in the atomic state at very low cryogenic temperature, where its energy is not released prematurely. A very light weight inhibitor, or other method of propellant conditioning would be needed. A premature release of the atom recombination energy will result in extremely high thrust, high acceleration, or explosion of the vehicle.

Solid particle feed systems can alleviate the problems of a monolit nic solid fuel grain. The analyses presented here illustrate the possible designs for launch vehicles using these feed systems. A two-stage vehicle was analyzed with the solid particle feed systems. Comparisons of the NLS design and GLOW (Ref. 1, 10) with the analyses of two-stage atomic Al, B, C, and $\mathrm{H}$ rockets was conducted. These comparisons will show the effects of the solid 
particle feed systems on GLOW of the vehicles. The vehicle mass is estimated using the traditional mass scaling relation:

$$
\text { Mdry }=\mathrm{A}+\mathrm{B} \cdot \mathrm{Mp}
$$

where:

Mdry vehicle dry mass, $\mathrm{kg}$

A fixed mass scaling parameter, $\mathrm{kg}$

B propellant dependent mass scaling parameter, $\mathrm{kg} / \mathrm{kg} \mathrm{Mp}$

Mp propellant mass, $\mathrm{kg}$

Each of these parameters was estimated with detailed tank mass estimation codes, and scaling from existing detailed designs (Ref. 10). The addition of He was also modeled, and all of the mass scaling equations are provided in Tables I through 4 . The tank maximum operating pressure was 50 psia, the rocket engines used a 30 psia chamber pressure, and we assumed the propellant is pressure fed. In the mission analysis for the atomic rockets, the total velocity change (delta $-\mathrm{V}$ ) was $9.700 \mathrm{~m} / \mathrm{s}$. which is more than $500 \mathrm{~m} / \mathrm{s}$ higher than the delta-V for the NLS design. This additional delta- $V$ should accommodate any performance losses or altitude compensation losses incurred with the lower engine chamber pressure. The vehicle diameter was 6.1 meters, and the tankage was cylindrical, with ellipsoidal dome ends.

A slurry or gel of solid hydrogen in liquid helium was considered to control the flow of the atom-solid particle propellants. The CET rocket performance code (Ref. 26) was used to estimate the effects on Isp for the addition of $\mathrm{He}$ as a carrier fluid. In general, the effect of the $\mathrm{He}$ on the vehicle should be a reduction in the lsp of the rocket, but there is also an increase in the propellant density, in some cases. The Isp drops due to the addition of the inert helium and the density of the propellant increases because the helium is a higher density fluid than the solid hydrogen. The Isp reduction is addressed in the rocket performance section. For the monopropellant atomic hydrogen rockets. the solid $\mathrm{H}_{2}$ particles (encapsulating the atomic $\mathrm{H}$ ) using a 40-wt\% liquid helium carrier has a density of $0.091 \mathrm{~g} / \mathrm{cm}^{3}$ for the cases that were investigated. The solid hydrogen with the encapsulated atoms has a density of $0.077 \mathrm{~g} / \mathrm{cm}^{3}$, about 15 percent lower density than the solid hydrogen liquid helium slurry or gel.

\section{Propellant Types}

Several different atomic species were analyzed as rocket propellants. The aluminum (Al), boron (B), carbon (C), and hydrogen $(\mathrm{H})$ atoms were stored (or encapsulated) in solid hydrogen, and a variety of helium mass loadings were used to investigate the performance changes due to the helium carrier fluid. In some cases, oxygen was used as an oxidizer (as a bipropellant), to improve the performance of the atomic $\mathrm{Al}$ rocket propellants. The $\mathrm{B}$. $\mathrm{C}$, and $\mathrm{H}$ propellants typically had very high Isp performance, and the addition of $\mathrm{O}_{2}$ would not increase the Isp values. Adding $\mathrm{O}_{2}$ to the $\mathrm{B}, \mathrm{C}$, and $\mathrm{H}$ fuel was investigated however, as an option to reducing the total mass of atomic propellants needed for the Earth to Orbit mission. Reducing the total amount of atomic propellants needed would simplify the ground support equipment at the launch site, and the propellant production facility.

\section{Atom Weight Percent}

The atom weight percent (wt\%) values are the mass of trapped atoms to the total mass of the atoms and the encapsulating solid $\mathrm{H}_{2}$. The atom wt\% values were selected based on the several criteria. A 5-mole percent (mole\%) loading in the solid $\mathrm{H}_{2}$ was selected based on past experimental results (Ref. 2). Current research has concluded that the maximum atom loading that may be possible in the near term is 5 -mole\%. The 5 -mole\% loading is translated to a wt $\%$ in Appendix A.

The $5 \mathrm{~mole} \%$ cases translate into different atom wt $\%$ for each propellant. With atomic hydrogen, the value is $2.5 \mathrm{wt} \%$. Based on CET Isp calculations, there is no Isp increase for this atomic fuel over $\mathrm{O}_{2} / \mathrm{H}_{2}$, thus a higher goal for atom storage must be set. If the Isp of the rocket is lower than $\mathrm{O}_{2} / \mathrm{H}_{2}$, the GLOW will be increased. and the complexity of the very low temperature cryogenics will not be considered worthwhile investment for a less than attractive Isp value. 
The Isp performance for the atomic monopropellants is much more attractive at higher atom wt $\%$ values. With $\mathrm{B}$ and $\mathrm{C}$, the Isp performance is more attractive: 689 seconds for B (at $60 \mathrm{wt} \%$ ), and 733 seconds for C (at $60 \mathrm{wt} \%$ ). Atomic $\mathrm{H}$ delivers an Isp value of 750 seconds (at $15 \mathrm{wt} \%$ ). An atomic Al rocket engine will deliver a low Isp at less than 390 seconds (at $80 \mathrm{wt} \%$ ), and seems to be unattractive.

The remaining cases that were analyzed include either the theoretical peak specific impulses of the propellant combinations, or Isp values where the GLOW of the atomic propellant vehicles was comparable to or lower than the $\mathrm{O}_{2} / \mathrm{H}_{2}$ vehicle GLOW. Many of these atom loadings are very high: $501060 \mathrm{wt} \%$. While these atom loadings are high compared to the near term practical maximum levels noted earlier (the 5 molar\%), they are nonetheless interesting cases. and represent the ultimate goals that should be pursued for successful use of atomic propellants in rocket propulsion systems.

\section{Atomic Propellant Densitics}

The overall density for the atomic propellants is computed using the equations in Appendix B. Tables 5 to 20 shows the propellant densities for the combinations used in the analyses. The fuel densities are dependent upon the mass fraction of atoms stored and the amount of helium carrier fluid used. The densities of the atom-solid $\mathrm{H} 2$ combinations (without $\mathrm{He}$ ) varied from $0.077 \mathrm{~g} / \mathrm{cm}^{3}$ (15-wt\% $\mathrm{H}_{\text {in } \mathrm{H}_{2}}$, Table 18$)$ to $149.73 \mathrm{~g} / \mathrm{cm}^{3}$ (50-wt $\% \mathrm{Al}$ in $\mathrm{H}_{2}$, Table 6). The analyses using a He carrier fluid were conducted with 10.20 , and $40-w t \%$ of He. The $40-w t \%$ He cases represent a mixture of 70 -volume $\%$ of the atom-solid $(\mathrm{H} / \mathrm{H} 2)$ combination, with 30 -volume\% He. This value was chosen as the maximum value of volume fraction for the solid $\mathrm{H} 2$ in slush hydrogen used in the National Aerospace Plane (NASP) program (Ref. 27). This 30 volume\% of liquid carrier was considered the minimum needed for the practical flow of slush $\mathrm{H}_{2}$.

\section{ATOMIC PROPELLANT ENGINE PERFORMANCE}

Several values of wt\% of stored atoms are used in the simulations, and the lower values represent wt\% judged to be possible with near term technology. A 5 mole\% value of atoms stored in a solid $\mathrm{H}_{2}$ is considered technically feasible in the near term. The mole\% is translated to wt\% values for this analysis. Table Al (Appendix A) shows the near term practical values of mole\% versus wt\% for the four propeliants. It will be shown later that to reduce launch vehicle GLOW. much higher values of atom storage will be required.

Tables 5 through 20 show the Isp performance degradation for usirg a helium carrier fluid to feed the particles to the recombination chamber. The heats of formation used in the CET code for the various atoms are listed in Appendix $\mathrm{C}$. In the cases with low atom mass fractions in the solid $\mathrm{H}_{2}(10$ to $15 \mathrm{wt} \%)$, the influence of the He is strong, and it significantly reduced Isp performance. At higher atom loadings ( $50 \mathrm{wt} \%$ ), the performance degradation is much lower, with a much reduced effect. The reduced Isp is also accor panied by an increase in propellant density with the atomic $\mathrm{H}$. This density increase is also evident with B and C, for their low atom wt \% cases: 22 and 24 wt\% respectively. At the higher atom wt $\%$ values, the density decreases as the He is added. All of the engines operated at a 30 psia chamber pressure with a 60:1 expansion ratio. A 95\% engine efficiency on Isp was assumed.

\section{Propellant Mixture Ratios (C/F)}

In addition to estimating the rocket Isp for the atomic propellants as monopropellants, the bipropellant Isp performance (with $\mathrm{O}_{2}$ as the oxidizer) was computed for several cases. These data were generated to illustrate the potential for reducing GLOW by using a higher density oxidizer, rather than a pure monopropellant. Also, if a hipropellant had an attractive performance level, then the production of the atomic fuel could be significantly reduced, thereby simplifying rocket launch operations and reducing the $\mathrm{c}$ :st and extent of atomic fuel production.

The Isp performances for the atomic fuels with $\mathrm{O}_{2}$ were also computed with the three levels of He addition: 10 , 20 and $40 \mathrm{wt} \%$. These data were also used in the selection of the O/F $\mathrm{for}$ the bipropellant cases, as the addition of $\mathrm{He}$ did have a strong effect on engine Isp. 


\section{Atomic Aluminum}

The predicted performance for aluminum is fairly low compared to $\mathrm{O}_{2} / \mathrm{H}_{2}$. As shown in Figure 2, the peak Isp is $390 \mathrm{~s}$, significantly lower than the $430 \mathrm{~s}$ Isp for the $\mathrm{O}_{2} / \mathrm{H}_{2}$ case. In the engine performance analyses, it was found that atomic Al Isp values were significantly increased with the use of $\mathrm{O}_{2}$ as an oxidizer. With $\mathrm{O}_{2}$ as an oxidizer, the Isp values increase and the maximal value is $507 \mathrm{~s}$ at an $\mathrm{O} / \mathrm{F}$ of 0.5 , and a $60 \mathrm{wt} \%$ of atomic Al. The atoms of aluminum have a high molecular weight (MW), and hence the addition of $\mathrm{O}_{2}$ reduces the exhaust $\mathrm{MW}$ and increases Isp. The Isp performance is still fairly low, however, and was dropped from consideration after performing some GLOW analyses.

\section{Atomic Boron}

Boron performance is high, over 600 seconds for many cases. Figure 3 shows the map of Isp values. A peak monopropellant performance of 689 seconds is delivered at a 60 -wt $\%$ of B atoms. At a 50-wt $\%$ atom loading, the Isp value was $651 \mathrm{~s}$. Adding $\mathrm{O}_{2}$ as an oxidizer did not increase the 50- and 60-wt $\%$ atomic $\mathrm{B}$ Isp over the monopropellant cases.

At 22-wt\%, the Isp does increase with the addition of $\mathrm{O}_{2}$. In Figure 4, the addition of He to the propellant (at an atom loading of 22-wt\%) showed that a peak Isp value occurs at an $\mathrm{O} / \mathrm{F}$ of 0.5 . The monopropellant Isp, sans $\mathrm{He}$, was $436 \mathrm{~s}$, whereas with an $\mathrm{O} / \mathrm{F}$ at 0.5 , the Isp ranged from $530 \mathrm{~s}$ (10-wt\% He) to $473 \mathrm{~s}(40$-wt $\%$ He). Figure 5 shows the effect of $\mathrm{He}$ with a $50-\mathrm{wt} \% \mathrm{~B}$ cases. At this high atom loading, the He has only a small effect on the rocket Isp.

\section{Atomic Carbon}

The atomic carbon engine performance is also very high, and it's Isp values were 696 seconds for the 50 -wt $\%$ atomic $\mathrm{C}$ case, and $733 \mathrm{~s}$ for the 60 -wt $\%$ case, as shown in Figure 6 . As with the atomic $\mathrm{B}$, adding $\mathrm{O}_{2}$ as an oxidizer will not increase Isp for the high atom wt\% cases. The monopropellant performance at a $24-w t \%$ level was $513 \mathrm{~s}$.

Figures 7 and 8 show the influence of $\mathrm{He}$ on the atomic C Isp at 24- and 50-wt\%, respectively. In the 24-wt\% atomic $\mathrm{C}$ case, the addition of $\mathrm{O}_{2}$, in general, decreased engine Isp. At an $\mathrm{O} / \mathrm{F}$ of 1.0 , the Isp is $504 \mathrm{~s}(10-\mathrm{wt} \% \mathrm{He})$ to $471(40-w t \% \mathrm{He})$. At this $\mathrm{O} / \mathrm{F}$ value, the Isp reduction due to the addition of $\mathrm{He}$ is relatively small compared to other $\mathrm{O} / \mathrm{F}$ values. This design point may be worth investigating in future launch vehicle optimizations.

\section{Alomic Hydrogen}

The performance with atomic $H$ was the highest of any of the cases investigated. It's Isp values range from 600 to nearly $1300 \mathrm{~s}$. In Figure 9, the highest monopropellant performance is 1500 seconds delivered at a 100 -wt $\%$ of $H$ atoms. It's unlikely that we will be able to store 100-wt\% of atomic $\mathrm{H}$, so the lower levels of 10, 15, and 50-wt\% were investigated in the GLOW analyses. Adding $\mathrm{O}_{2}$ as an oxidizer will not increase Isp.

Figure 10 shows the monopropellant performance for atomic $\mathrm{H}$ with both equilibrium and frozen flow. There is a potential for the high wi \% atomic hydrogen engine cases to act as a frozen flow, instead of an equilibrium flow. Additional analyses of the combustion assuming frozen flow could be conducted, and the reduction in rocket Isp assessed. All of the analyses presented in this paper use equilibrium flow results, and hence may be optimistic for the high atom wt\% cases.

The effect of He on Isp was computed for the 10-wt\% and the 50-wt \% atomic $\mathrm{H}$ cases, and is shown in Figures 11 and 12, respectively. In the 10 -wt $\%$ case, the addition of He always reduced Isp, but the Isp influence seemed smallest at the O/F value of 1.0. As with the atomic $\mathrm{C}$ cases, these $\mathrm{O} / \mathrm{F}$ analyses may he useful in future launch vehicle optimization. With the $50-w 1 \%$ case, the addition of He reduced the Isp, but its effect was relatively small compared to the $10-w t \%$ case. 


\section{GLOW RESULTS AND COMPARISONS}

In Figures 13 through 16, the GLOW values of the four atomic propellant launch vehicles are presented. In most cases, the minimum wt $\%$ atomic propellant cases (corresponding to 5 -mole\%) did not produce Isp values high enough to allow a GLOW reduction over $\mathrm{O}_{2} / \mathrm{H}_{2}$ technology. Several higher atom storage cases were run to determine the minimum Isp needed for allowing a GLOW reduction. The cases included the atom stored in $\mathrm{H}_{2}$ as a monopropellant and some cases with $\mathrm{O}_{2}$ as an oxidizer. Additional cases were run to investigate the effect of helium addition at the 10,20 , and $40-w t \%$ levels.

\section{Atomic Aluminum}

The cases with atomic Al are very poor performers when compared with $\mathrm{O}_{2} / \mathrm{H}_{2}$ technology. As a monopropellant, all of the predicted specific impulse values were 390 seconds. Using $\mathrm{O}_{2}$ as an oxidizer does improve the overall performance level, to nearly 493 to $507 \mathrm{~s}$ Isp, but the overall additional mass for the tankage and structure does not allow the vehicle to deliver a GLOW reduction. Figure 13 shows the GLOW comparison for atomic $\mathrm{Al}$ with $\mathrm{O}_{2} / \mathrm{H}_{2}$. Even with the high 49.3.1 second Isp value (using an $\mathrm{O} / \mathrm{F}$ of 0.5 , and $50-\mathrm{wt} \%$ atomic $\mathrm{Al}$ ), the vehicle GLOW was still greater than the $\mathrm{O}_{2} / \mathrm{H}_{2}$ vehicle by $27 \%$. Because of its poor performance, this propellant type was dropped from further consideration.

\section{Atomic Boron}

Atomic B has a very good chance of reducing the GLOW of the vehicle when compared with $\mathrm{O}_{2} / \mathrm{H}_{2}$ propellants. The only drawback is that the B atom wt $\%$ must be 50 or 60 percent, which is more than double the $22 \mathrm{wt} \%$ value. The $22-w t \%$ cases produced a GLOW of 4.85 times that of $\mathrm{O} 2 / \mathrm{H} 2$ vehicle. Using a value of 50 and $60-\mathrm{wt} \%$ $B$, the GLOW was reduced significantly: by 40 and $50 \%$ respectively

Helium addition had a powerful effect in increasing the GLOW. Figure 14 shows the sensitivity of GLOW to helium addition, with the 22,50 , and 60 -wt $\%$ B atom cases. The $60 \mathrm{wt} \%$ cases were least affected, but the $22 \mathrm{wt} \%$ cases produce unusually large GLOW values: up to 43.5 times the GLOW of the $\mathrm{O} 2 / \mathrm{H} 2$ case. Clearly the 22 -wt\% cases will not be attractive for this application. With the 50-wt\% cases, the addition of 10-wt\% He does not severely affect the vehicle GLOW, but as the He goes up to 40 -wt $\%$, the vehicle GLOW is higher than the $\mathrm{O}_{2} / \mathrm{H}_{2}$ case.

\section{Atomic Carbon}

The monopropellant atomic $\mathrm{C}$ cases at the 50 and 60 -wt $\%$ levels had reduced GLOW values over the $\mathrm{O}_{2} / \mathrm{H}_{2}$ baseline. However, a 24-w1\% atomic C case did not produce a GLOW reduction. The GLOW increase for the monopropellant case with no $\mathrm{He}$ was $74 \%$.

Figure 15 presents the GLOW results for atomic $\mathrm{C}$. The atomic $\mathrm{C}$ ، ases produced generally higher Isp values that the atomic B cases, and so their predicted GLOW values were less affected by the addition of He. Both the 50 and $60-\mathrm{wt} \%$ cases were able to deliver GLOW reductions even after adding the $40-\mathrm{wt} \%$ He.

\section{Atomic Hydrogen}

Figure 16 illustrates the GLOW values for atomic $\mathrm{H}$. With atomic $\mathrm{f}$, no GLOW reductions were possible until a $15-\mathrm{wt} \%$ of atoms were used. At the $10-\mathrm{wt} \% \mathrm{H}$ level, the atomic $\mathrm{H}$ GLOWW was $4 \%$ greater than the $\mathrm{O}_{2} / \mathrm{H}_{2}$ baseline. At a $15-w t \%$ level, the GLOW is reduced by $44 \%$. With a $50-w 1 \%$ aton loading, the GLOW is reduced by $78 \%$.

When adding He to the flow for the 10 -wt $\%$ Atomic $\mathrm{H}$ cases, the G.LOW is $22 \%$ to $106 \%$ higher than the baseline case. as shown in Figure 16. The 15-wt\% atomic $\mathrm{H}$ cases only exceed the baseline GLOW when the He is at a $40-\mathrm{wt} \%$ level. The range of GLOW reduction for the $15-\mathrm{wt} \%$ cases was from $37 \%$ (with $10-\mathrm{wt} \% \mathrm{He}$ addition) to a GLOW increase of $6 \%$ with the 40 -wt $\%$ He added. The 50-wt $\%$ atomic $\mathrm{H}$ cases are almost unaffected by the $\mathrm{He}$ addition. The GLOW reduction is $72 \%$ over the $\mathrm{O}_{2} / \mathrm{H}_{2}$ vehicle GLOW, even with the 40 -wt \% He addition. 


\section{DISCUSSION AND OBSERVATIONS}

Atomic B demonstrated very high performance and good GLOW reductions over $\mathrm{O}_{2} / \mathrm{H}_{2}$, but only if the stored atom values are above 50-wt\%. Atomic $\mathrm{C}$ also demonstrated excellent performance and ability to reduce GLOW over $\mathrm{O}_{2} / \mathrm{H}_{2}$ vehicles. As with the atomic B cases, the highest GLOW reductions are possible at the higher atom wt $\%$ levels: 50 - and 60 -wt $\%$. The higher atom loadings demonstrated a good insensitivity to He addition, which will be important for any vehicle using a cryogenic solid particle feed system at a $4 \mathrm{~K}$ temperature.

With atomic $\mathrm{H}$ at a 10 -wt \% level, no GLOW reductions over $\mathrm{O}_{2} / \mathrm{H}_{2}$ vehicles were possible. At 15 -wt\% atomic $\mathrm{H}$, there were very significant GLOW reductions, for all but the 40 -wt $\%$ He addition case. The 50 -wt $\%$ atom cases showed a strong insensitivity to He addition.

Mass summaries of the promising atomic $\mathrm{C}$ and $\mathrm{H}$ vehicle showing their subsystem masses for each of their two stages are provided in Tables 21 , and 22, respectively. The atomic $\mathrm{C}$ vehicle used a 50-wt\% atom loading, and the atomic $\mathrm{H}$ vehicle used a $15-\mathrm{w} 1 \%$ atom loading, and no He addition. The masses for the subsystems are generally conservative, especially the structural masses, which are typically 7 percent of the propellant mass. A $20 \%$ contingency mass is added to the dry weights of the vehicles as well. This contingency level is conservative, based on past preliminary space vehicle design rules, and it accommodates many design unknowns. The delta-V used for the vehicle sizing is also conservative, at over $9.700 \mathrm{~m} / \mathrm{s}$ for the trip to low Earth orbit. This higher than usual delta-V value can also accommodate many design unknowns in both dry mass and engine performance.

Very few combustion tests have been conducted with atomic propellants, and therefore it's difficult to predict the exact combustion efficiency. In such a high energy rocket engine, it will be difficult to extract all of the energy noted in the predicted rocket engine Isp. Engine efficiency sensitivity studies should be conducted on all of the cases in this paper.

The selection of $\mathrm{H}_{2}$ as the solid cryogen for atom storage is very likely. Hydrogen is an excellent rocket propellant, and can add significant energy due to the atom recombination, as well as combustion. Other solid cryogens that have been considered are solid neon and argon. These solids have been used in atom storage experiments, and may be viable candidates is some ground-based applications. Their lower combustion energies and higher molecular weights do not make them as attractive as $\mathrm{H}_{2}$, hut further investigations are warranted, if higher temperature storage of atoms becomes desirable.

The engine and vehicle efficiency is also most strongly influenced by the ability to flow the 4-K temperature fuel to a $2000-\mathrm{K}$ (or higher temperature) engine, while preventing premature atom recombination. The heat transfer between the feed system components, the engine, and the propellant will create a major engineering challenge. During the transfer of the 4-K atom-solid hydrogen-helium slurry or gel, the temperature of the fuel must not vary more than a few degrees. The atoms will begin to recombine if the solid hydrogen softens. Additionally, the engine will be quite hot - about $2000 \mathrm{~K}$ temperature in the recombination -combustion chamber for the atomic hydrogen cases. Maintaining the integrity of the frozen hydrogen with the trapped atoms will be difficult. to say the least. Specialized insulation techniques, or other synergistic cooling techniques, to lower the heat flux to the feed system will no doubt have to be developed. Heat transfer investigations will be needed to create a unique and effective highly integrated engine and feed system design.

\section{CONCLUSIONS}

Atomic $B$ and $C$ had significant increases in Isp over $\mathrm{O}_{2} / \mathrm{H}_{2}$. With $\mathrm{B}$ and $\mathrm{C}$. the Isp performance was 689 seconds for $B$ (at $60 \mathrm{wt} \%$ ), and 733 seconds for $C$ (at $60 \mathrm{wt} \%$ ). Atomic $H$ delivers an Isp value of 750 seconds (at $15 \mathrm{wt} \%$ ). An atomic Al rocket engine will deliver a low Isp at less than 390 seconds (at $80 \mathrm{wt} \%$ ). This low Isp does not reduce the vehicle GLOW, and therefore atomic Al seems to be an unattractive propellant.

Atomic $\mathrm{H}$ delivers that highest possible Isp increases, but the propellant must be stored at least a $15-\mathrm{wt} \%$ level to deliver a significant GLOW reduction over $\mathrm{O}_{2} / \mathrm{H}_{2}$.

Several values of wt \% of stored atoms were investigated, and the lowest values noted represent the wt\% judged to he possible with near term technology. A 5 mole\% value of atoms stored in a solid cryogen, such as $\mathrm{H}_{2}$, is consid ered technically feasible in the near term. However, to deliver a reduction in vehicle GLOW, much higher values of atom storage will be required.

The GLOW of launch vehicles using atomic B, C, and $\mathrm{H}$ was significantly reduced over that for $\mathrm{O}_{2} / \mathrm{H}_{2}$ propellants. Atomic B reduced GLOW by 12 to $50 \%$ at a $60-\mathrm{wt} \%$ atom level. Atomic $\mathrm{C}$ allowed GLOW reductions of 8 to 
$48 \%$ (at a 50-wt\% level) and atomic $\mathrm{H}$ the predicted GLOW savings is up to $44 \%$ at a 15 -wt $\%$ atom level, and up to $78 \%$ with a 50 -wt\% of atom storage. Adding $\mathrm{He}$ to the fuel to create a gel or slurry with the solid $\mathrm{H}_{2}$ particles does reduce rocket Isp, but the overall effect is small at the highest atom wt values.

\section{CONCLUDING REMARKS}

Atomic Al did not have any significant performance increase over $\mathrm{O}_{2} / \mathrm{H}_{2}$, and hence the GLOW for these vehicles was very high. The atomic Al cases were not investigated extens vely, but their performance may prove useful in very high density applications.

Helium addition to the atomic fuels reduced performance, but the performance effects were very small for high atom mass fractions: above $60 \mathrm{wt} \%$. At the lower atom loadings of $50-\mathrm{wt} \%$, the He addition has a sizable effect, but the atomic vehicle GLOW was still lower than or comparable to the $\mathrm{O}_{2} / \mathrm{H}_{2}$ vehicle GLOW. Methods of flowing solid $\mathrm{H}_{2}$ particles with small wt\% values of $\mathrm{He}$ will therefore be desirable.

Additional analyses can be conducted for atomic $\mathrm{Al}, \mathrm{B}, \mathrm{H}$, and $\mathrm{C}$, carried in solid hydrogen with liquid helium. In some cases, the density of the combination of atoms and the solid hydrogen may be overestimated, as it is unknown as to what are the exact interactions of the atoms and the solid $\mathrm{H}_{2}$ once the atoms are stored in the $\mathrm{H}_{2}$. Therefore, in addition to the using the densities noted for atomic Al, B, and $\mathrm{C}$, a worst-case lowest density assumption of $0.077 \mathrm{~g} / \mathrm{cm}^{3}$ atomic fuel density can be assumed for the different propellants.

Stored atoms in solid hydrogen are the penultimate step in the development of higher performance. higher density propellants. Future vehicle and engine designs using atom-based propellants have the potential to deliver sizable performance improvements over traditional chemical propulsion systems, as well as commercial benefits (Ref. 29). Commercial aspects of the propellants are being addressed in current research programs. The advanced propellants will require longer development times, so they will take a lenger time to be commercialized than more traditional propellants. Elements that are related to the propellant feed system technology might be commercialized in the near future. Near term prospects related to these high energy species might be in the following areas: production methods of the atoms or species, the cryogenic feed system components, superinsulation, valves, flow control and flow measurement components, feed lines, cryogenic storage, and leak detection systems.

Atomic propellants, such as B, C, and H, have an enormous potential for high Isp operation, and their pursuit has been a topic of great interest for decades. Recent and continuing advances in the understanding of matter, and the development of new technologies of simulating matter at it's most basic level, and manipulating matter through micro- and nanotechnology will no doubt create a bright and exciting future for atomic propellants. 
Appendix A-Specific impulses for 5-mole\% atom cases

Table A L - Weight $\%$ values for 5 -mole\% of atoms in solid $\mathrm{H}_{2}$

\begin{tabular}{|l|c|l|}
\hline Atom & $\begin{array}{c}\text { Weight } \\
\text { (for } 5 \text {-mole } \% \text { ) }\end{array}$ & \multicolumn{1}{|c|}{$\begin{array}{c}\text { Monopropellant } \\
\text { lsp (s) }\end{array}$} \\
\hline $\mathrm{Al}$ & 41.0 & less than $400^{*}$ \\
$\mathrm{~B}$ & 22.0 & 436 \\
$\mathrm{C}$ & 24.0 & 513 \\
$\mathrm{H}$ & 2.6 & less than $400^{*}$ \\
\hline
\end{tabular}

Expansion ratio $=60 ; 1$. Chamber pressure $=30$ psia.

*Performance not calculated hy CET, as the exit

temperature is too low to complete the calculation.

Appendix B-Propellant Densities

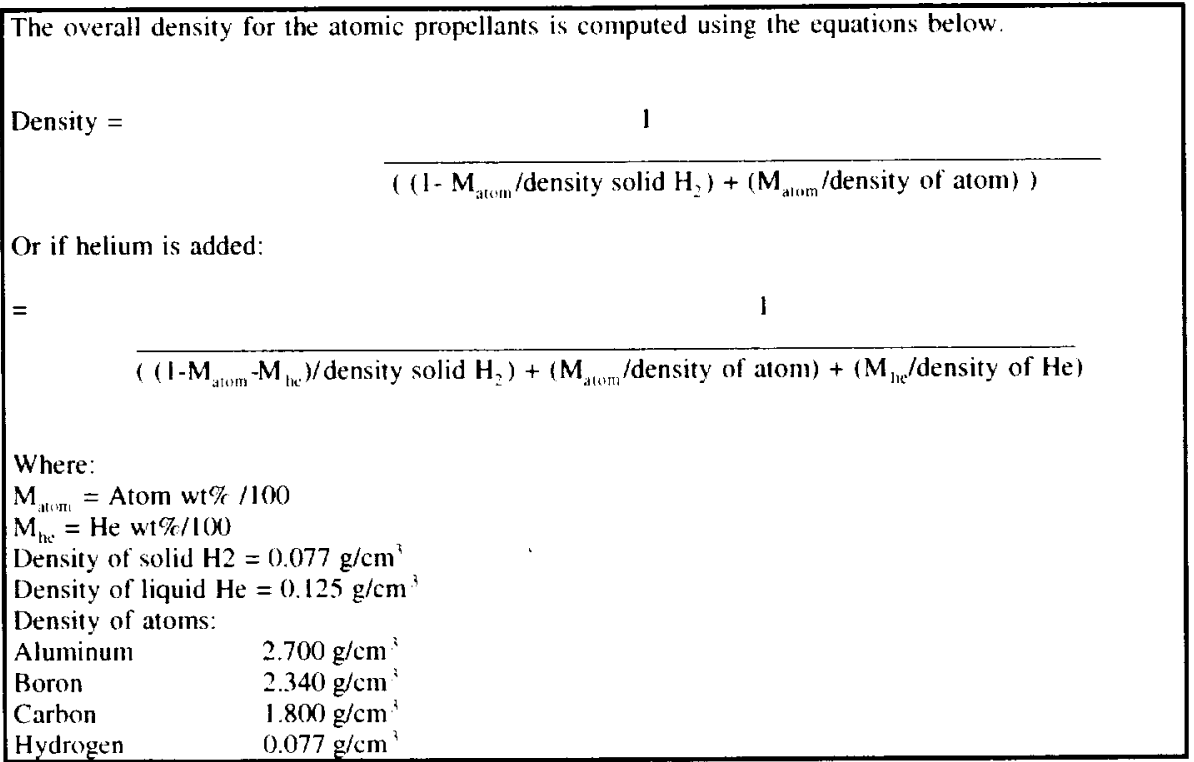

\section{Appendix C-CET Heat of Formation Input Data}

Table Cl. - Heat of Formation for fuel components - All components at $4 \mathrm{~K}$, except $\mathrm{O}_{2}$, at $90 \mathrm{~K}$

\begin{tabular}{|c|c|}
\hline Component & Heat of formation (cal/mole) \\
\hline Al atom & $78,800.0$ \\
B atom & 135.000 .0 \\
C atom & 171.300 .0 \\
H atom & 52.200 .0 \\
H (s) & $1-2.210 .0$ \\
He (l) & $5-1.477 .8$ \\
$\mathrm{O}_{2}$ (l) & $-3,102.0$ \\
\hline
\end{tabular}

"Ref 11

Ref. 28.

Ref. 26. 


\section{REFERENCES}

1. Palaszewski, B.: "Atomic Hydrogen Propellants: Historical Perspectives and Future Possibilities," NASA Lewis Research Center, AIAA 93-0244, presented at the 31 st AJAA Aerospace Science Meeting, Reno, NV, January II-14. 1993.

2. Carrick. P., and Tam, S., Editors: "Proceedings of the High Energy Density Materials (HEDM) Contractors' Conference held 4-7 June 1995 in Woods Hole, MA," USAF Phillips Laboratory, Report Number PL-TR-953039. January 1996.

3. Thompson, T.L., and Rodgers, S.L.. Editors: "Proceedings of the High Energy Density Materials (HEDM) Contractors' Conference held 5-7 June 1994 in Crystal Bay, NV," USAF Phillips Laboratory, Report Number PL-TR-94-3036. December 1994.

4. Thompson. T.L., Editor: "Proceedings of the High Energy Density Materials (HEDM) Contractors' Conference held 6-8 June 1993 in Woods Hole, MA," USAF Phillips Laboratory, Report Number PL-TR-93-3041, November 1993.

5. Berman, M., Editor: "Proceedings of the High Energy Density Materials (HEDM) Contractors' Conference held 5-7 June 1992 in Crystal Bay, NV," Air Force Office of Scientific Research, November 1992.

6. Thompson. T.L.. Editor: "Proceedings of the High Energy Density Materials (HEDM) Contractors" Conference held 24-27 February 1991 in Albuquerque, NM," USAF Phillips Laboratory, Report Number PL-TR-91 3003, October 1991.

7. Davis, L., and Wodarczyk, F., Editors: "Proceedings of the High Energy Density Materials (HEDM) ContracIors' Conference, 25-28 February 1990, Long Beach, CA." Air Force Office of Scientific Research, May 1990.

8. Wiley, T.G, and van Opinjnen. R.A., Editors: "Proceedings of the High Energy Density Materials (HEDM) Contractors" Conference held 12-15 March 1989 in New Orleans, LA," USAF Astronautics Laboratory (AFSC), Report Number AL-CP-89-002, July 1989.

9. Davis. L.. and Wodarczyk, F., Editors: "Proceedings of the High Energy Density Materials (HEDM) ContracIors" Conference, 28 February-2 March 1988, Newport Beach, CA," Air Force Office of Scientific Research. May 27, 1988.

10. Palaszewski, B.: "Atomic Hydrogen As A Launch Vehicle Propellant," NASA-Lewis Research Center, AIAA 90-0715, presented at the 28th AIAA Aerospace Science Meeting, Reno, NV, January 8-11, 1990.

11. Carrick. P.: "Specific Impulse Calculations of High Energy Density Solid Cryogenic Rocket Propellants, 1: Atoms in Solid Hydrogen." USAF Phillips Laboratory Report PL TR-93-3014, April 1993.

12. Collins, G., et al.: "Triggered Energy Releases in Solid Hydrogen Hosts Containing Unpaired Atoms," Physical Review Letters, Vol. 65, No. 4, pp. 444-447, July 23, 1990.

13. Lee. T.J., and Rice. J.E.: "Theoretical Characterization Of Tetraheiral N4," Journal of Chemical Physics, Vol. 94, Jan. 15, 1991, pp. 1215-1221.

14. Segal, C.. Friedauer, M.J., Udaykumar, H.S., Shyy, W., and Marchand, A.P.: "Ignition Characteristics Of A New High-Energy Density Fuel In High-Speed Flows." Journal of Propulsion and Power, Vol. 13, No. 2, Mar.-Apr. 1997, pp. 246-249.

15. Seidl, E.T., Schaefer, H.F., III, "Theoretical Studies Of Oxygen Rings-Cyclotetraoxygen, (O4)," Journal of Chemical Phisics, Vol. 88, June 1, 1988, pp. 7043-7049.

16. Gordon. E.B.. et al.: "Metastable Impurity-Helium Solid Phase: Ex serimental and Theoretical Evidence," Chemical Physics, Vol. 170, (1993), pp. 411-426.

17. Scharf. D., et al.: "Nature of Lithium Trapping Sites in the Quantum Solids Para-Hydrogen and OrthoDeuterium." Journal of Chemical Physics, Vol. 99, No. 11. December 1993, pp. 9013-90120.

18. Eaton. P., Or, Y., and Branca. S.: "Pentaprismane," Journal of the American Chemical Society, Vol. 103 (1981), pp. 21.34-2136.

19. Matsunaga. N. and Gordon. S.: "Stabilities and Energetics of Inorg unic Benzene Isomers: Prismanes," Journal of the American Chemical Societs. Vol. 166, (1994), pp. 11407-1419.

20. Lauderdale, W., Stanton, J., Bartlett, R.: "Stability and Energetics of Metastable Molecules: Tetraazatetrahedrane (N4). Hexaazabenzene (N6), and Octaazacubane (N8)," Journal of Physical Chemistry, Vol. 96, (1992). pp. 1173-1178.

21. Watts, J.D. and Bartlett. R.J.: "Coupled-cluster calculations on the $\mathrm{C} 2$ molecule and the $\mathrm{C} 2(+)$ and $\mathrm{C} 2(-)$ molecular ions," Journal of Chemical Physics, Vol. 96, April 15, 1992, pp. 6073-6084. 
22. Fajardo, M.E., "Limitations On Stored Energy Densities In Systems Of Separated Ionic Species, “Joumal of Propulsion and Power, Vol. 8, Jan.-Feb. 1992, pp. 30-36.

23. Fajardo, M., Carrick. P., and Kenney, J. III, "Matrix Isolation Spectroscopy Of Metal Atoms Generated By Laser Ablation. I - The Li/Ar, Li/Kr, And Li/Xe Systems," Journal Of Chemical Physics, Vol. 94, May I, 1991, pp. 5812-5825.

24. Brazier, C. and Carrick, P.: "Observation Of Several New Electronic Transitions Of The B2 Molecule," Journal Of Chemical Physics, Vol. 96, No. 12, June 15, 1992, pp. 8684-8690.

25. Palaszewski, B., lanovski, L., and Carrick, P.: "Propellant Technologies: A Persuasive Wave of Future Propulsion Benefits," presented at the $3^{\text {rd }}$ International Symposium on Space Propulsion, Beijing, China, August 11-13, 1997.

26. McBride, B. and Gordon, S.: "Computer Program for Calculation of Complex Chemical Equilibrium Compositions and Applications. Part 1: Analysis," NASA RP-1311, October 1994.

27. Hardy, T.: "FLUSH: A Tool for the Design of Slush Hydrogen Flow," NASA TM-102467, February 1990.

28. McCarty. R.: "Thermophysical Properties of Helium-4 from 4 to $3000 \mathrm{R}$ with Pressures to $15000 \mathrm{psia}$," National Bureau of Standards (NBS) Technical Note 622, NASA CR-128445, September 1, 1972.

29. Bushnell, D.: "Far Term Visions: The Frontiers of the Responsibly Imaginable," Transportation Beyond 2000: Technologies Needed for Engineering Design. pp. 261-295. Feb. 1, 1996. 


TABLE 1.-ATOMIC ALUMINUM
MASS SCALING EQUATIONS
\begin{tabular}{|c|c|c|}
\hline He wi\% & A. $\mathrm{kg}$ & B, $\mathrm{kg} / \mathrm{kg} \mathrm{Mp}$ \\
\hline \multicolumn{3}{|c}{$50 \mathrm{wt} \%$ Atomic Al. O/F $=0.50$} \\
\hline 0 & 11.517 .0 & 0.211136 \\
\hline
\end{tabular}

TABLE 2.-ATOMIC BORON MASS SCALING EQUATIONS

\begin{tabular}{|c|c|c|}
\hline He w1\% & A. kg & B. kg/ kg Mp \\
\hline \multicolumn{3}{|c|}{$22 \mathrm{wt} \%$ Atomic B. O/F $=0.00$} \\
\hline 0 & $11,934.3$ & 0.293811 \\
\hline 10 & 11.934 .3 & 0.293357 \\
\hline 20 & 11.934 .3 & 0.289915 \\
\hline 40 & 11.934 .3 & 0.283021 \\
\hline \multicolumn{3}{|c|}{$22 \mathrm{wt} \%$ Atomic B. O/F $=0.50$} \\
\hline 00 & 11.517 .0 & 0.247787 \\
\hline \multicolumn{3}{|c|}{$50 \mathrm{wt} \%$ Atomic B. O/F $=0.00$} \\
\hline 0 & 11.934 .3 & 0.242283 \\
\hline 10 & 11.934 .3 & 0.244281 \\
\hline 20 & 11.934 .3 & 0.246290 \\
\hline 40 & 11.934 .3 & 0.250301 \\
\hline \multicolumn{3}{|c|}{$60 \mathrm{wt} \%$ Atomic B. O/F $=0.00$} \\
\hline 0 & 11.934 .3 & 0.222803 \\
\hline 10 & 11.934 .3 & 0.226758 \\
\hline 20 & 11.934 .3 & 0.230708 \\
\hline 40 & 11.934 .3 & 0.238616 \\
\hline \multicolumn{3}{|c|}{} \\
\hline
\end{tabular}

TABLE 3.-ATOMIC CARBON MASS SCALING EQUATIONS

\begin{tabular}{|l|c|c|}
\hline He wi\% & A. kg & B. kg/kg Mp \\
\hline $24 \mathrm{wt} \%$ Atomic C, $\mathrm{O} / \mathrm{F}=0.00$ \\
\hline 0 & 11.934 .3 & 0.293403 \\
\hline 10 & 11.934 .3 & 0.290286 \\
\hline 20 & 11.934 .3 & 0.287177 \\
\hline 40 & 11.934 .3 & 0.280970 \\
\hline $24 \mathrm{wt} \%$ & Atomic C. O/F $=1.00$ \\
\hline 00 & 11.934 .3 & 0.221568 \\
\hline $50 \mathrm{wl} \%$ & Atomic C. O/F $=0.00$ \\
\hline 0 & 11.934 .3 & 0.243276 \\
\hline 10 & 11.934 .3 & 0.245180 \\
\hline 20 & 11.934 .3 & 0.247086 \\
\hline 40 & 11.934 .3 & 0.250895 \\
\hline $60 \mathrm{wt} \%$ Alomic C. O/F $=0.00$ \\
\hline 0 & 11.934 .3 & 0.223998 \\
\hline 10 & 11.934 .3 & 0.227831 \\
\hline 20 & 11.934 .3 & 0.231671 \\
\hline 40 & 11.934 .3 & 0.239 .328 \\
\hline
\end{tabular}

TABLE 4.-ATOMIC HYDROGEN MASS SCALING EQUATIONS

\begin{tabular}{|c|c|c|}
\hline He wt\% & $\mathrm{A}, \mathrm{kg}$ & $\mathrm{B}, \mathrm{kg} / \mathrm{kg} \mathrm{Mp}$ \\
\hline \multicolumn{3}{|c|}{$10 \mathrm{wt} \%$ Atomic $\mathrm{H}, \mathrm{O} / \mathrm{F}=0.00$} \\
\hline 0 & $11,934.3$ & 0.339661 \\
\hline 0 & $11,934.3$ & 0.331936 \\
\hline .0 & $11,934.3$ & 0.324184 \\
\hline 10 & $11,9.34 .3$ & 0.308675 \\
\hline \multicolumn{3}{|c|}{$1.5 \mathrm{wt} \%$ Atomic $\mathrm{H} . \mathrm{O} / \mathrm{F}=0.00$} \\
\hline 0 & $11,934.3$ & 0.339661 \\
\hline 0 & 11.934 .3 & 0.331936 \\
\hline 20 & 11.934 .3 & 0.324184 \\
\hline 40 & 11.934 .3 & 0.308675 \\
\hline \multicolumn{3}{|c|}{$50 \mathrm{w} 1 \%$ Atomic $\mathrm{H}, \mathrm{O} / \mathrm{F}=0.00$} \\
\hline 0 & $11,934.3$ & 0.339661 \\
\hline 0 & 11.934 .3 & 0.331936 \\
\hline 20 & 11.934 .3 & 0.324184 \\
\hline 30 & $11,934.3$ & 0.308675 \\
\hline
\end{tabular}

TABLE 5.-ATOMIC ALUMINUM ENGINE PERFORMANCE AND PROPELLANT DENSITY

\begin{tabular}{|c|c|c|}
\hline \multicolumn{3}{|c|}{41 wt\% Atomic Al, O/F $=0.5$} \\
\hline He w1\% & $\begin{array}{c}\text { Fuel density. } \\
\mathrm{g} / \mathrm{cm}^{3}\end{array}$ & Isp (s) \\
\hline$j$ & 0.1280 & $\mathrm{n} / \mathrm{a}$ \\
\hline 0 & 0.1277 & 454.8 \\
\hline 20 & 0.1274 & 441.4 \\
\hline 40 & 0.1268 & 413.3 \\
\hline
\end{tabular}

TABLE 6.-ATOMIC ALUMINUM ENGINE PERFORMANCE AND PROPELLANT DENSITY

\begin{tabular}{|c|c|c|}
\hline \multicolumn{3}{|c|}{50 wi\% Alomic Al, O/F $=0.5$} \\
\hline He: wi\% & $\begin{array}{c}\text { Fuel density. } \\
\mathrm{g} / \mathrm{cm}^{3}\end{array}$ & Isp (s) \\
\hline 0 & 0.1497 & 493.1 \\
\hline 10 & 0.1468 & 479.9 \\
\hline 20 & 0.1440 & 465.7 \\
\hline 40 & 0.1388 & 434.0 \\
\hline
\end{tabular}

TABLE 7.-ATOMIC BORON ENGINE PERFORMANCE AND PROPELLANT DENSITY

\begin{tabular}{|c|c|c|}
\hline \multicolumn{3}{|c|}{22 wt\% Atomic B. O/F $=0.0$} \\
\hline$H: w 1 \%$ & $\begin{array}{c}\text { Fuel density, } \\
\mathrm{g} / \mathrm{cm}^{3}\end{array}$ & Isp (s) \\
\hline 0 & 0.0978 & 435.5 \\
\hline 10 & 0.1000 & 411.7 \\
\hline 20 & 0.1023 & 385.6 \\
\hline 40 & 0.1071 & 329.6 \\
\hline
\end{tabular}


TABLE 8.-ATOMIC BORON ENGINE PERFORMANCE AND PROPELLANT DENSITY

$50 \mathrm{wt} \%$ Atomic B, $\mathrm{O} / \mathrm{F}=0.0$

\begin{tabular}{|c|c|c|}
\hline He wt\% & $\begin{array}{c}\text { Fuel density, } \\
\mathrm{g} / \mathrm{cm}^{3}\end{array}$ & Isp (s) \\
\hline 0 & 0.1491 & 651.2 \\
\hline 10 & 0.1463 & 624.7 \\
\hline 20 & 0.1436 & $\mathrm{n} / \mathrm{a}$ \\
\hline 40 & 0.1384 & 522.3 \\
\hline
\end{tabular}

TABLE 8-ATOMIC BORON ENGINE PERFORMANCE AND PROPELLANT DENSITY

\begin{tabular}{|c|c|c|}
\hline \multicolumn{3}{|c|}{50 wi\% Alomic B, $\mathrm{O} / \mathrm{F}=0.0$} \\
\hline He wt\% & $\begin{array}{c}\text { Fuel density. } \\
\mathrm{g} / \mathrm{cm}^{3}\end{array}$ & Isp (s) \\
\hline 0 & $0.149 !$ & 651.2 \\
\hline 10 & 0.1463 & 624.7 \\
\hline 20 & 0.1436 & $\mathrm{n} / \mathrm{a}$ \\
\hline 40 & 0.1384 & 522.3 \\
\hline
\end{tabular}

TABLE 10.-ATOMIC BORON ENGINE PERFORMANCE AND PROPELLANT DENSITY $22 \mathrm{wt} \%$ Atomic B. O/F $=0.5$

\begin{tabular}{|c|c|c|}
\hline He wt\%: & $\begin{array}{c}\text { Fuel density, } \\
\mathrm{g} / \mathrm{cm}^{3}\end{array}$ & lsp (s) \\
\hline 0 & $0 .(9978$ & 518.9 \\
\hline 10 & 0.1000 & 502.5 \\
\hline 20 & 0.1023 & 485.5 \\
\hline 40 & 0.1071 & 449.1 \\
\hline
\end{tabular}

TABLE 11.-ATOMIC BORON ENGINE PERFORMANCE AND PROPELLANT DENSITY 50) $w \%$ Atonic B. O/F $=0.25$

\begin{tabular}{|c|c|c|}
\hline \multicolumn{3}{|c|}{50 wt\% Atonic B. $\mathrm{O} / \mathrm{F}=0.25$} \\
\hline He wt\% & Fuel density. g/cm & Isp (s) \\
\hline 0 & 0.1491 & 632.0 \\
\hline 10 & 0.1463 & 614.1 \\
\hline 20 & 0.1436 & 594.5 \\
\hline 40 & 0.1384 & $\mathrm{n} / \mathrm{a}$ \\
\hline
\end{tabular}

TABLE 12.-ATOMIC CARBON ENGINE PERFORMANCE AND PROPELLANT DENSITY

\begin{tabular}{|c|c|c|}
\hline \multicolumn{3}{|c|}{24 wt\% Atomic $\mathrm{C}, \mathrm{O} / \mathrm{F}=0.0$} \\
\hline He wt\% & Fuel density, g/cm & lsp (s) \\
\hline 0 & 0.1000 & 512.5 \\
\hline 10 & 0.1020 & 488.0 \\
\hline 20 & 0.1041 & 462.0 \\
\hline 40 & 0.1087 & 402.8 \\
\hline
\end{tabular}

TABLE 13-ATOMIC CARBON ENGINE PERFORMANCE AND PROPELLANT DENSITY

\begin{tabular}{|c|c|c|}
\hline \multicolumn{3}{|c|}{$50 \mathrm{wt} \%$ Atomic C. $\mathrm{O} / \mathrm{F}=0.0$} \\
\hline He wi\% & $\begin{array}{c}\text { Fuel density. } \\
\mathrm{g} / \mathrm{cm}^{3}\end{array}$ & Isp (s) \\
\hline 0 & 0.1477 & 696.3 \\
\hline 10 & 0.1451 & 668.5 \\
\hline 20 & 0.1425 & 638.3 \\
\hline 40 & 0.1377 & 570.7 \\
\hline
\end{tabular}

TABLE 14.-ATOMIC CARBON ENGINE PERFORMANCE AND PROPELLANT DENSITY

\begin{tabular}{|c|c|c|}
\hline \multicolumn{3}{|c|}{$60 \mathrm{wi} \%$ Atomic C. ()$/ \mathrm{F}=0.0$} \\
\hline He wt\% & $\begin{array}{c}\text { Fuel density. } \\
\mathrm{g} / \mathrm{cm}^{2}\end{array}$ & Isp (s) \\
\hline 0 & 0.1809 & 733.4 \\
\hline 10 & 0.1732 & 712.2 \\
\hline 20 & 0.1660 & 684.5 \\
\hline 40 & 0.1535 & 612.5 \\
\hline
\end{tabular}

TABLE 15.-ATOMIC CARBON ENGINE PERFORMANCE AND PROPELLANT DENSITY

\begin{tabular}{|c|c|c|}
\hline \multicolumn{3}{|c|}{$24 \mathrm{wt} \%$ Atomic C. O/F $=1.0$} \\
\hline He wt\% & $\begin{array}{c}\text { Fuel density. } \\
\text { g/cm }\end{array}$ & Isp (s) \\
\hline 0 & 0.1000 & 487.8 \\
\hline 10 & 0.1020 & 478.2 \\
\hline 20 & 0.1041 & 468.4 \\
\hline 40 & 0.1087 & 447.3 \\
\hline
\end{tabular}


TABLE 16.-ATOMIC CARBON ENGINE PERFORMANCE AND PROPELLANT DENSITY

\begin{tabular}{|c|c|c|}
\hline \multicolumn{2}{|c|}{$50 \mathrm{wt} \%$} & Atomic C, O/F $=0.25$ \\
\hline $\mathrm{He} w t \%$ & $\begin{array}{c}\text { Fuel density. } \\
\mathrm{g} / \mathrm{cm}^{2}\end{array}$ & Isp (s) \\
\hline 0 & 0.1477 & 644.7 \\
\hline 10 & 0.1451 & 621.1 \\
\hline 20 & 0.1425 & 595.9 \\
\hline 40 & 0.1377 & 539.9 \\
\hline
\end{tabular}

TABLE 17.-ATOMIC HYDROGEN ENGINE PERFORMANCE AND PROPELLANT DENSITY

\begin{tabular}{|c|c|c|}
\hline \multicolumn{3}{|c|}{$10 \mathrm{wt} \%$ Atomic $\mathrm{H}, \mathrm{O} / \mathrm{F}=0.0$} \\
\hline $\mathrm{He} w t \%$ & $\begin{array}{c}\text { Fuel density, } \\
\mathrm{g} / \mathrm{cm}^{3}\end{array}$ & Isp (s) \\
\hline 0 & 0.0770 & 611.8 \\
\hline 10 & 0.0801 & 583.2 \\
\hline 20 & 0.0834 & 551.1 \\
\hline 40 & 0.0910 & $\mathrm{n} / \mathrm{a}$ \\
\hline
\end{tabular}

TABLE 18.-ATOMIC HYDROGEN ENGINE PERFORMANCE AND PROPELLANT DENSITY

\begin{tabular}{|c|c|c|}
\hline \multicolumn{3}{|c|}{15 wi\% Atomic H. O/F $=0.0$} \\
\hline He wt\% & $\begin{array}{r}\text { Fuel density. } \\
\mathrm{g} / \mathrm{cm}^{\%}\end{array}$ & Isp (s) \\
\hline 0 & 0.0770 & 750.0 \\
\hline 10 & 0.0801 & 713.4 \\
\hline 20 & 0.0834 & 674.4 \\
\hline 40 & 0.0910 & 587.6 \\
\hline
\end{tabular}

TABLE 19.-ATOMIC HYDROGEN ENGINE PERFORMANCE AND PROPELLANT DENSITY

\begin{tabular}{|c|c|c|}
\hline \multicolumn{3}{|c|}{$50 \mathrm{wt} \%$ Atomic H. O/F $=0.0$} \\
\hline He wt\% & $\begin{array}{c}\text { Fuel density. } \\
\mathrm{g} / \mathrm{cm}^{*}\end{array}$ & Isp (s) \\
\hline 0 & 0.0770 & 1281.5 \\
\hline 10 & 0.08011 & 1231.1 \\
\hline 20 & 0.0834 & 1176.2 \\
\hline 40 & 0.0910 & 1046.0 \\
\hline
\end{tabular}

TABLE 20-ATOMIC HYDROGEN ENGINE PERFORMANCE AND PROPELLANT DENSITY

\begin{tabular}{|c|c|c|}
\hline \multicolumn{3}{|c|}{50 wt\% Atonic H. O/F $=0.25$} \\
\hline He wt\% & $\begin{array}{c}\text { Fuel density. } \\
\text { g/cm }\end{array}$ & Isp (s) \\
\hline 0 & 0.0770 & 1156.3 \\
\hline 10 & 0.0801 & 1112.4 \\
\hline 20 & 0.0834 & 1065.0 \\
\hline 40 & 0.0910 & 954.7 \\
\hline
\end{tabular}

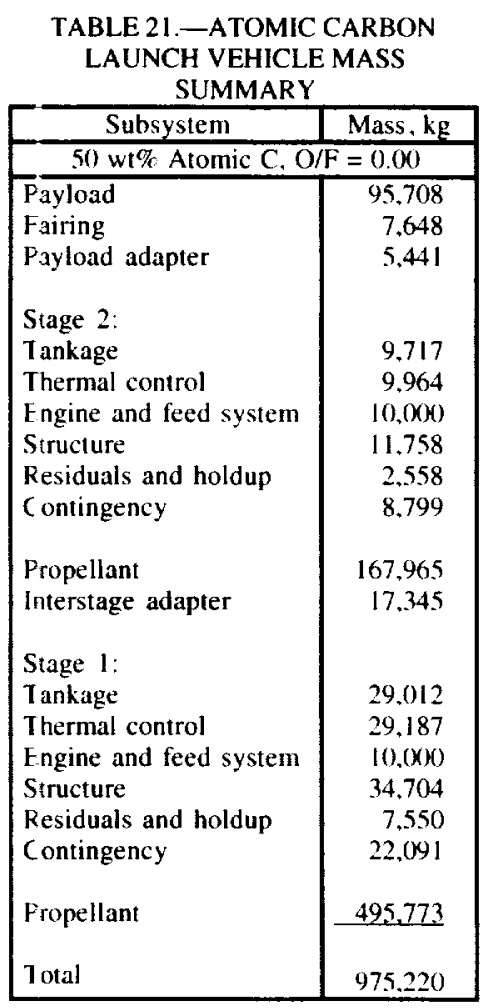

TABLE 22.-ATOMIC HYDROGEN LAUNCH VEHICLE MASS

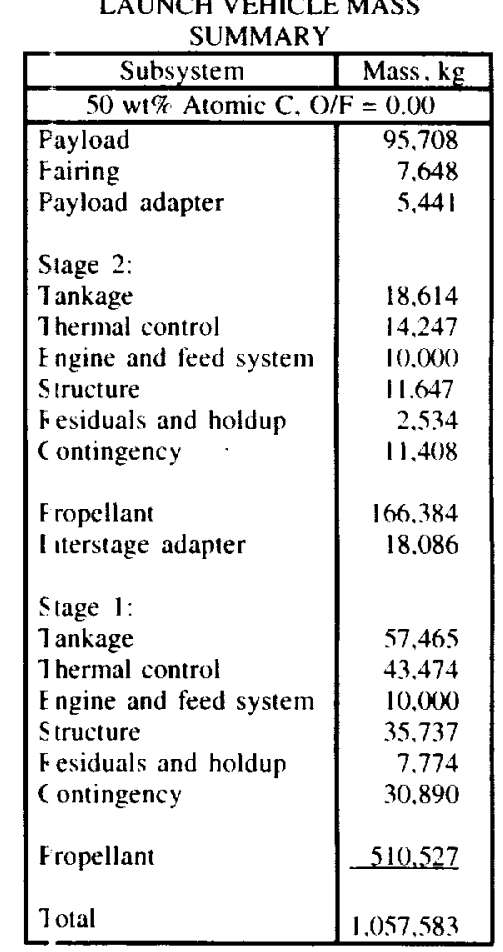




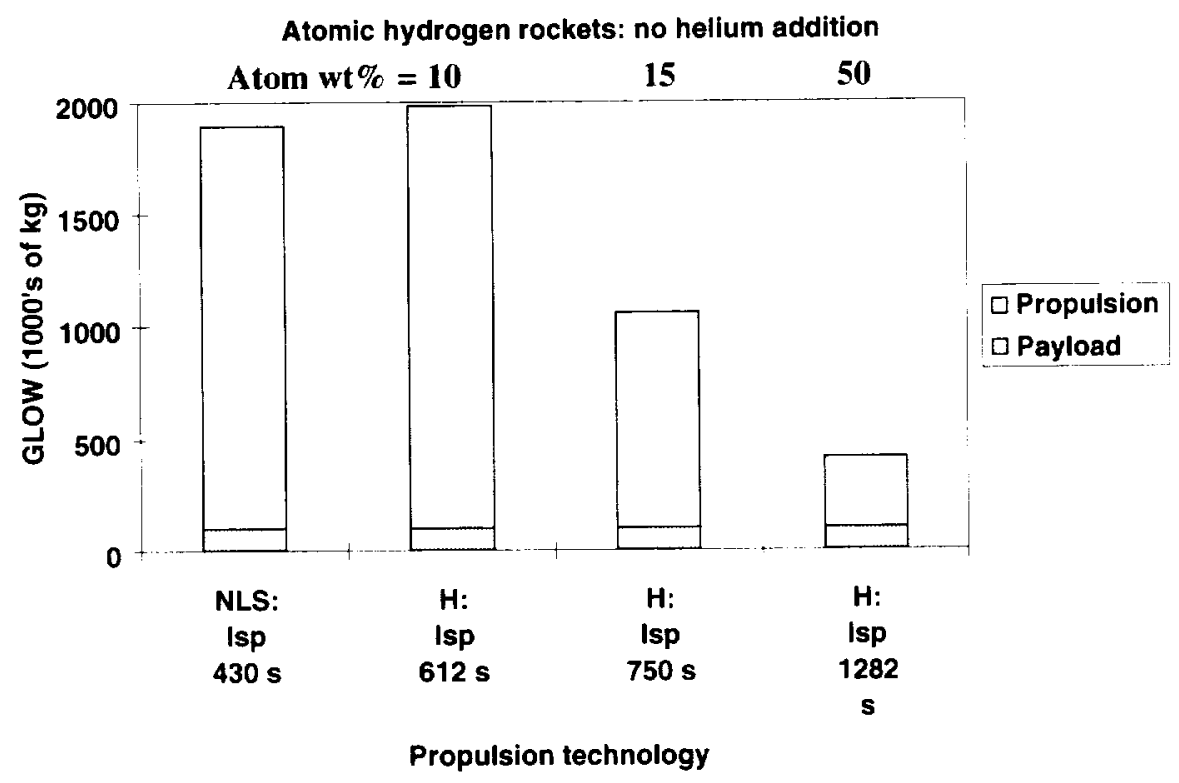

Figure 1.-Atomic hydrogen GLOW: monopropellant $\mathrm{H} / \mathrm{H} 2$, no helium addition.

Atomic aluminum engine performance: $\mathrm{O} 2$ as oxidizer

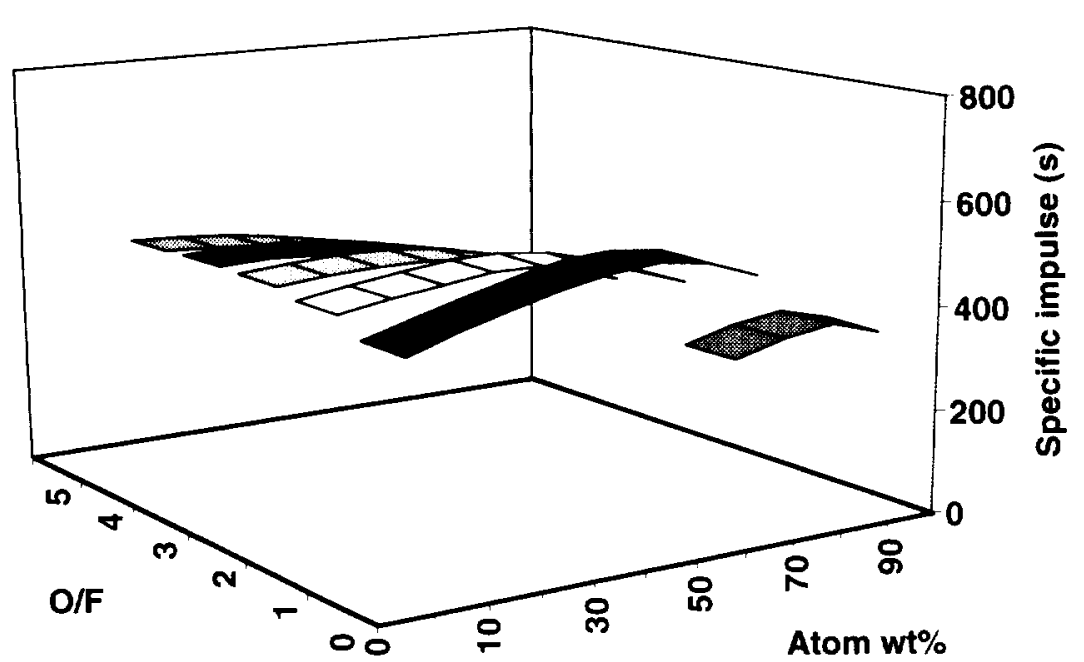

Figure 2.-Atomic aluminum engine performance. 
Atomic boron engine performance: $\mathrm{O} 2$ as oxidizer

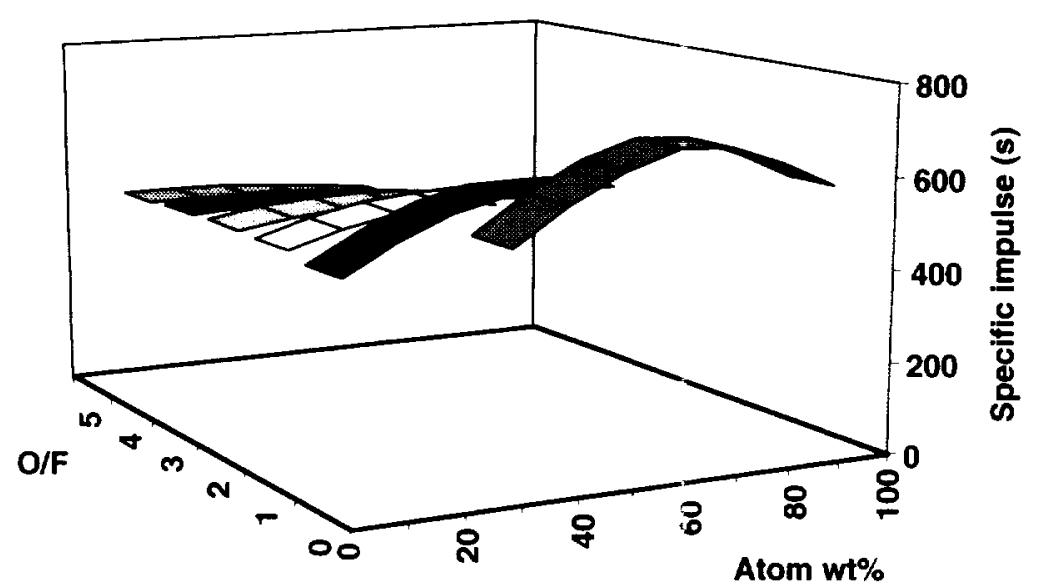

Figure 3.-Atomic boron engine performance.

Atomic boron: 22-wt\%, with helium

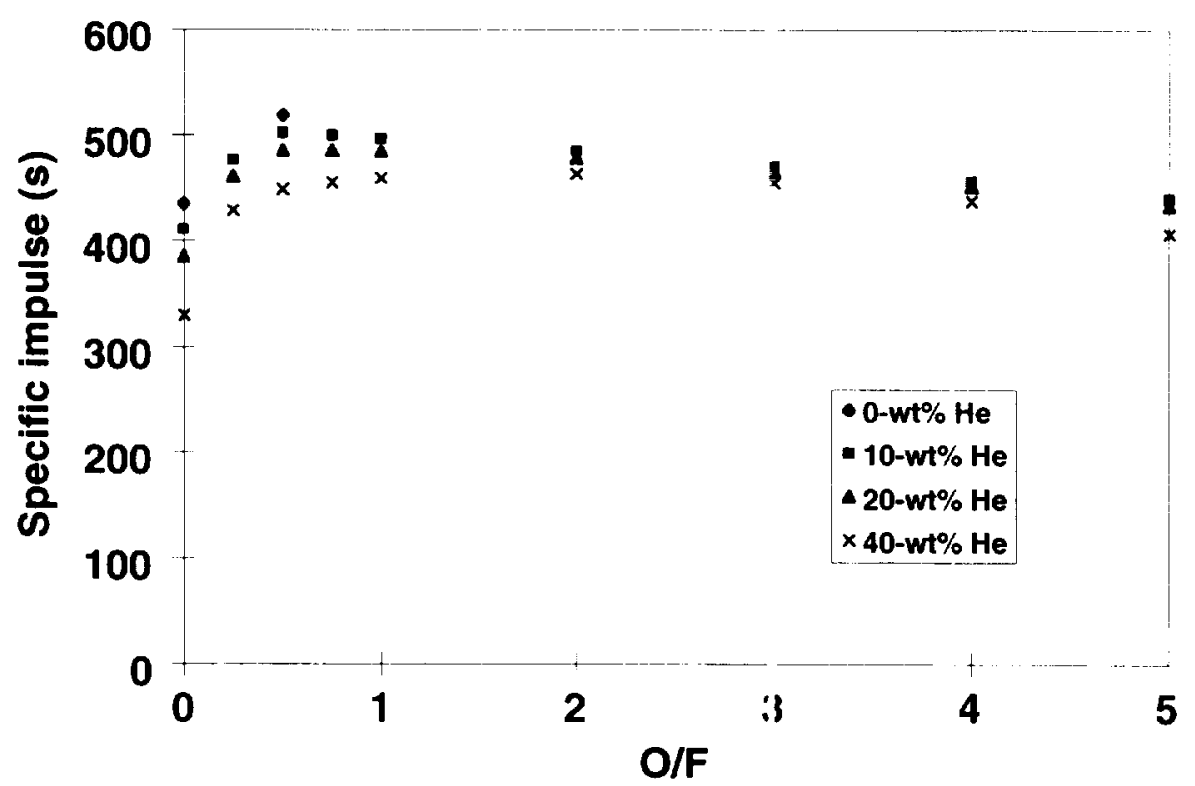

Figure 4.-Atomic aluminum engine performance. 


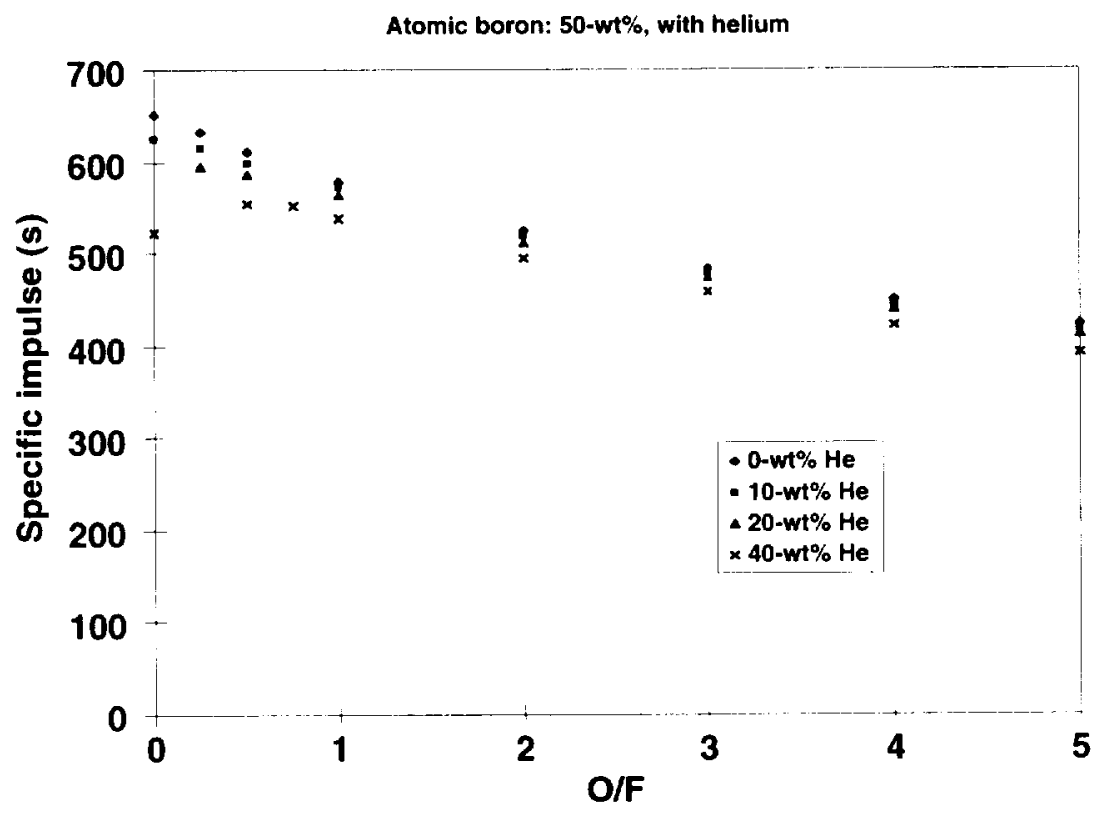

Figure 5.-Atomic boron engine performance.

Atomic carbon engine performance: $\mathrm{O} 2$ as oxidizer

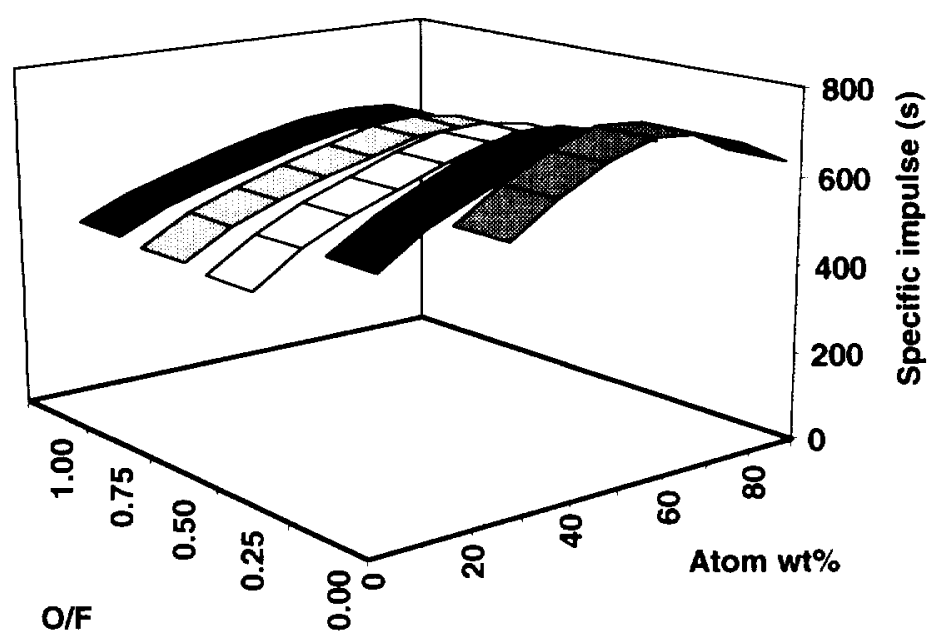

Figure 6.-Atomic carbon engine performance. 


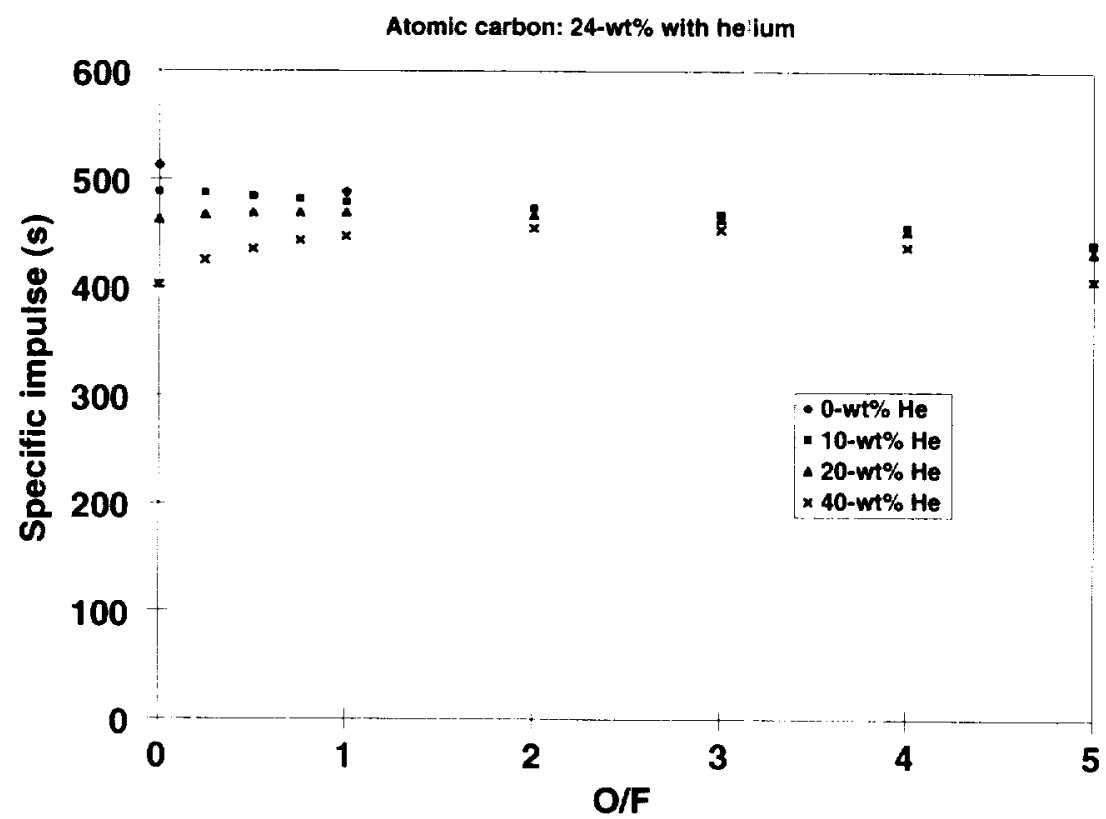

Figure 7.-Atomic carbon engine Isp: helium addition.

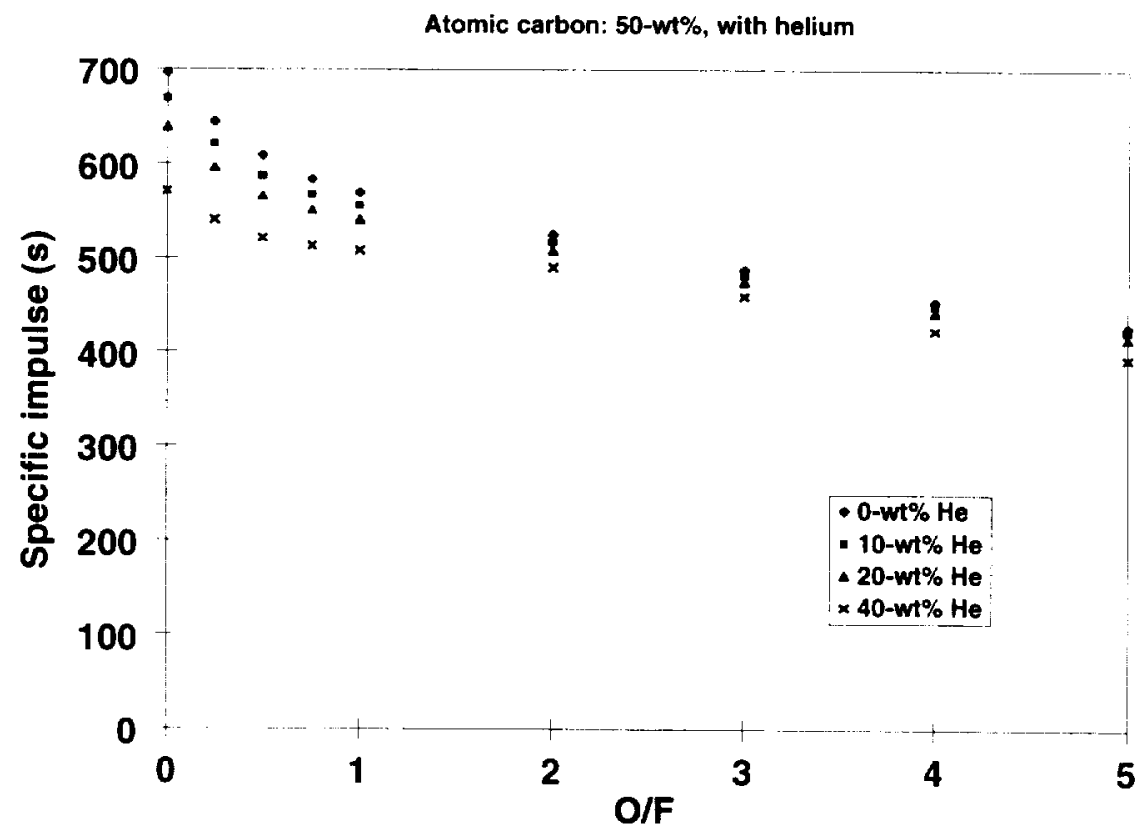

Figure 8.-Atomic carbon engine Isp: helium addition. 
Atomic hydrogen engine performance: $\mathbf{O 2}$ as oxidizer

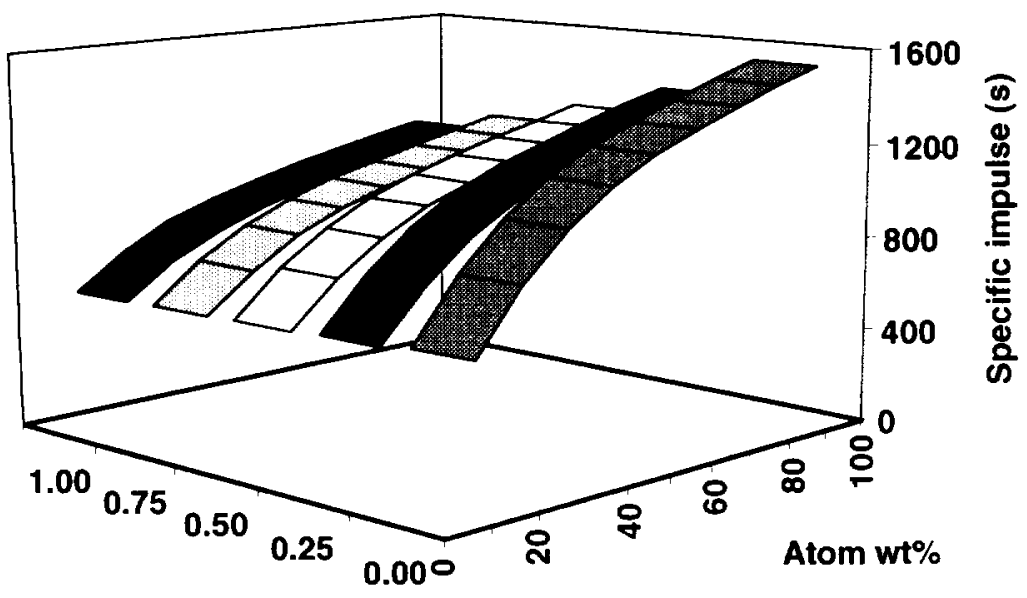

O/F

Figure 9.-Atomic hydrogen engine performance.

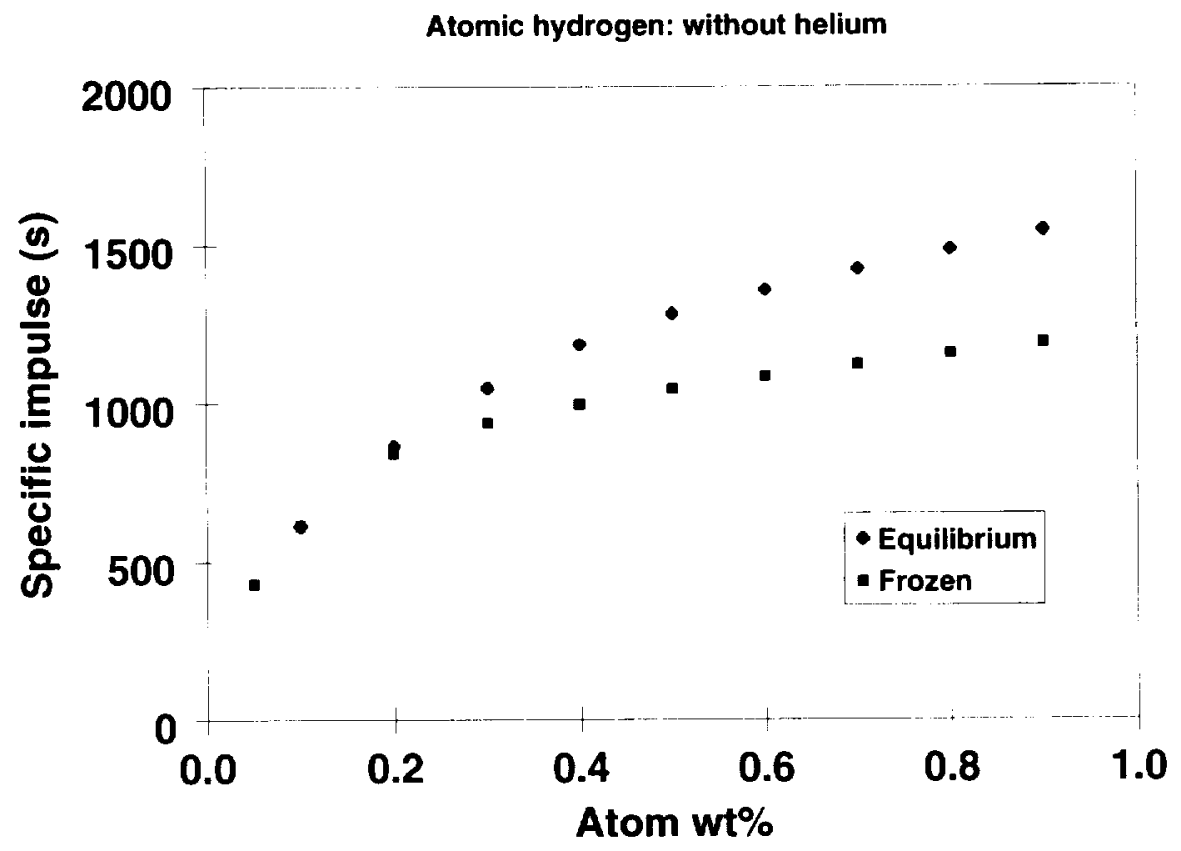

Figure 10.-Atomic hydrogen engine performance. 
Atomic hydrogen: $10-w t \%$, with helium

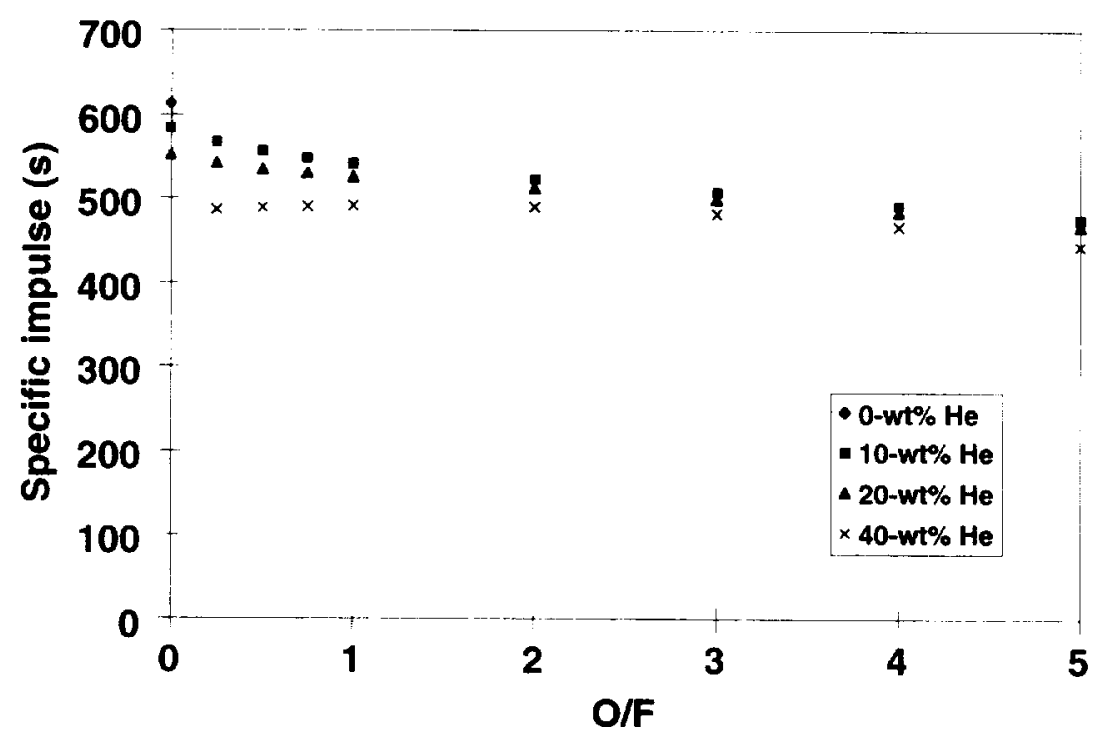

Figure 11.-Atomic hydrogen engine IsF: helium addition.

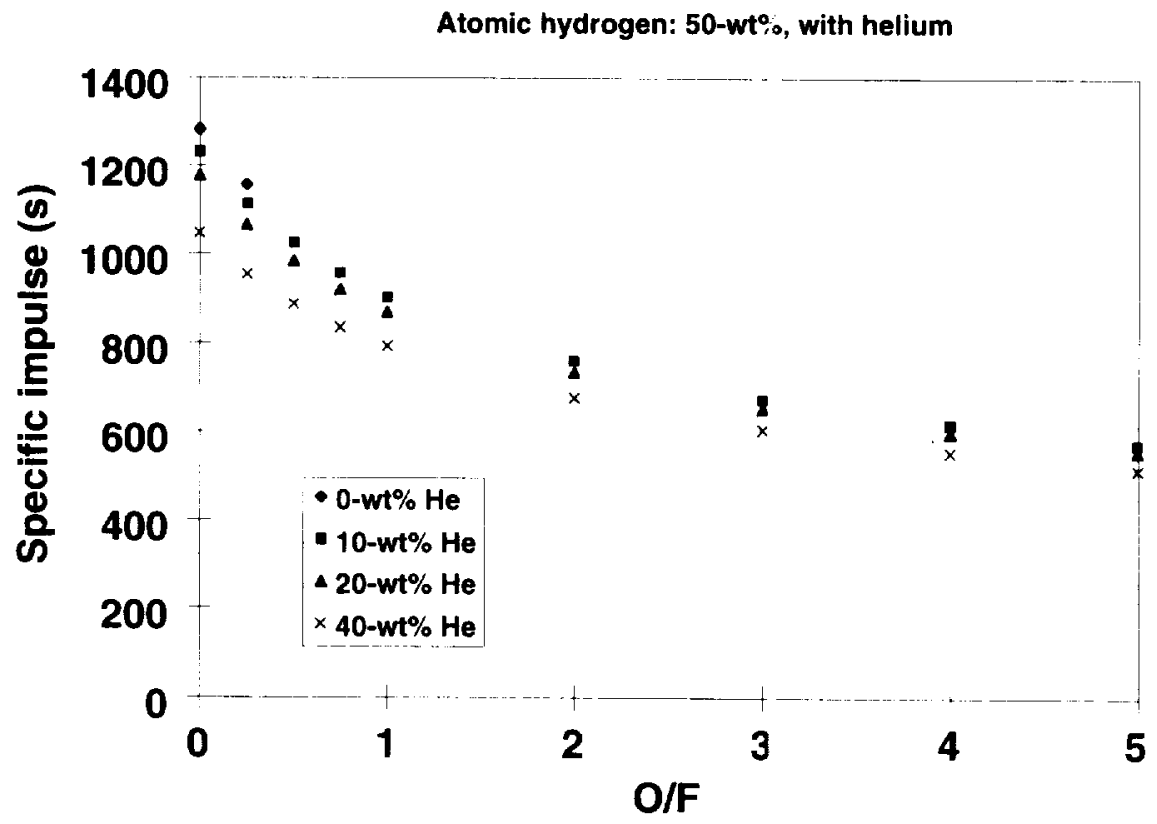

Figure 12.-Atomic hydrogen engine Isp: helium addition. 


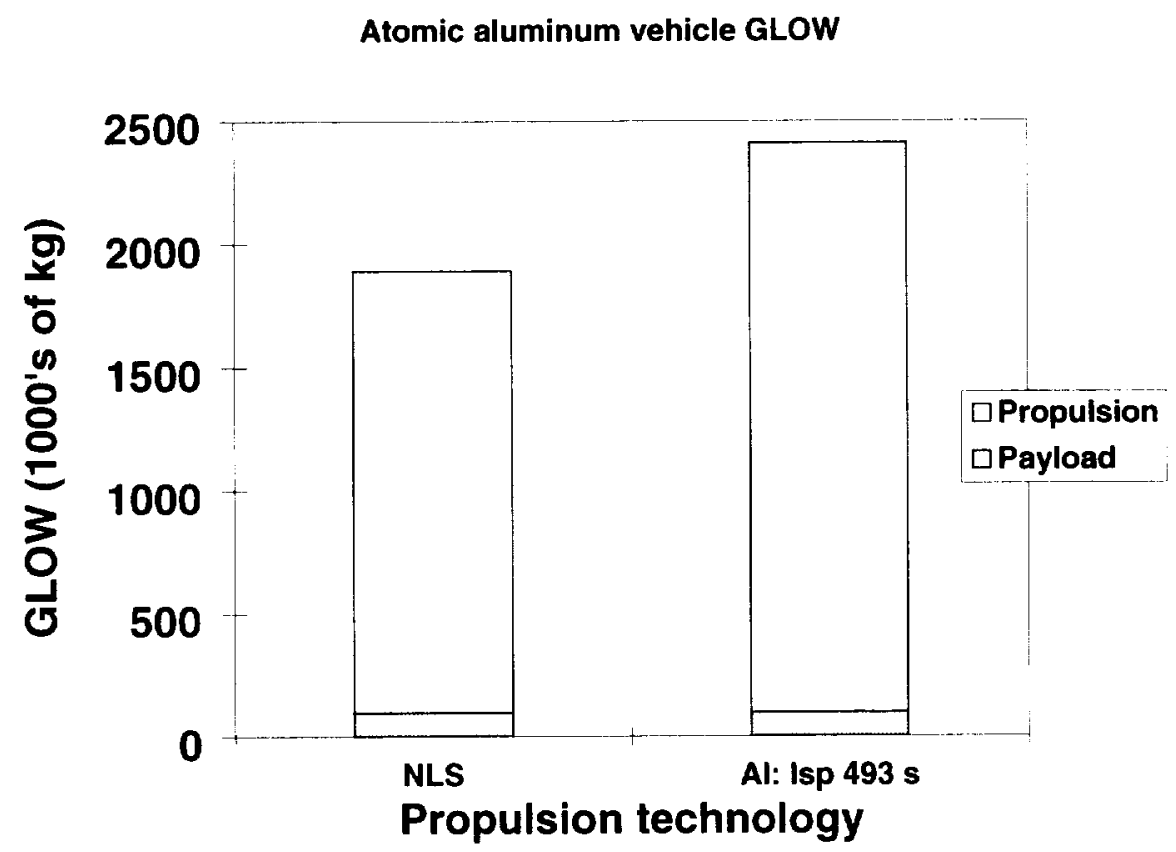

Figure 13.-Atomic aluminum vehicle GLOW.

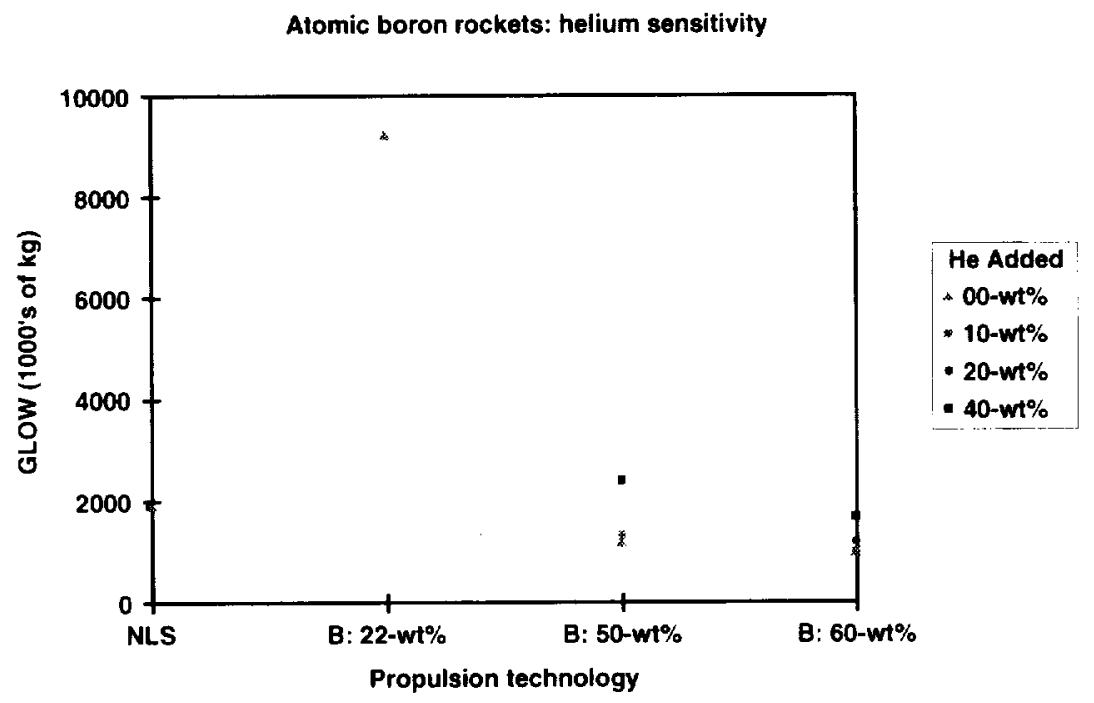

Figure 14.-Atomic boron vehicle GLOW. 


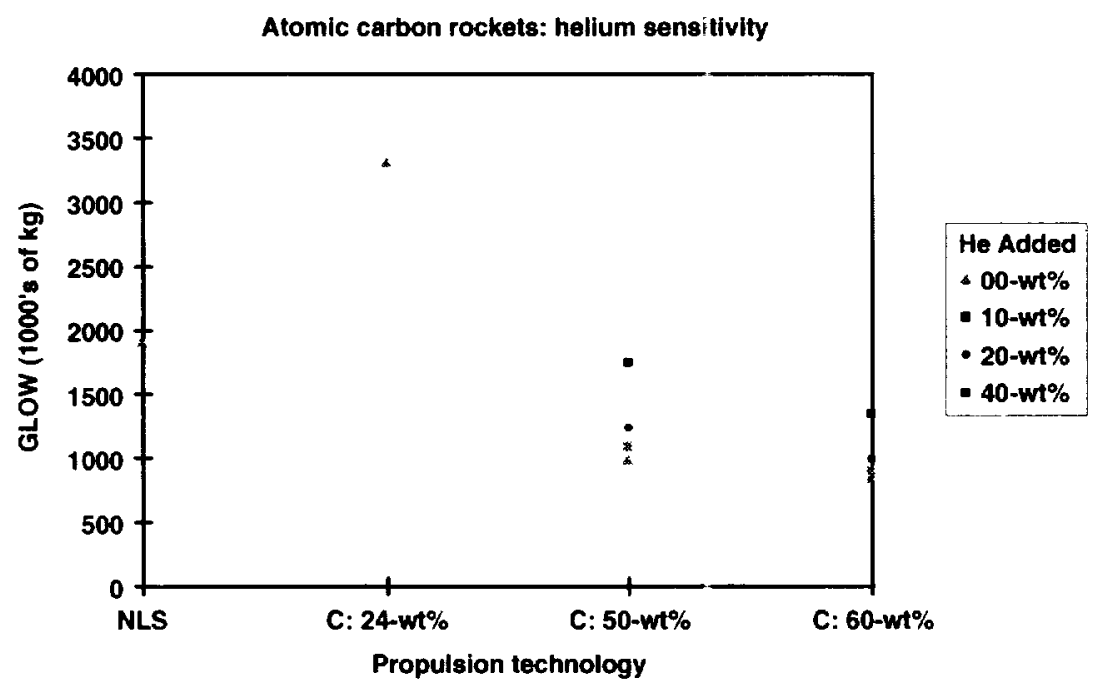

Figure 15.-Atomic carbon vehicle GLOW.

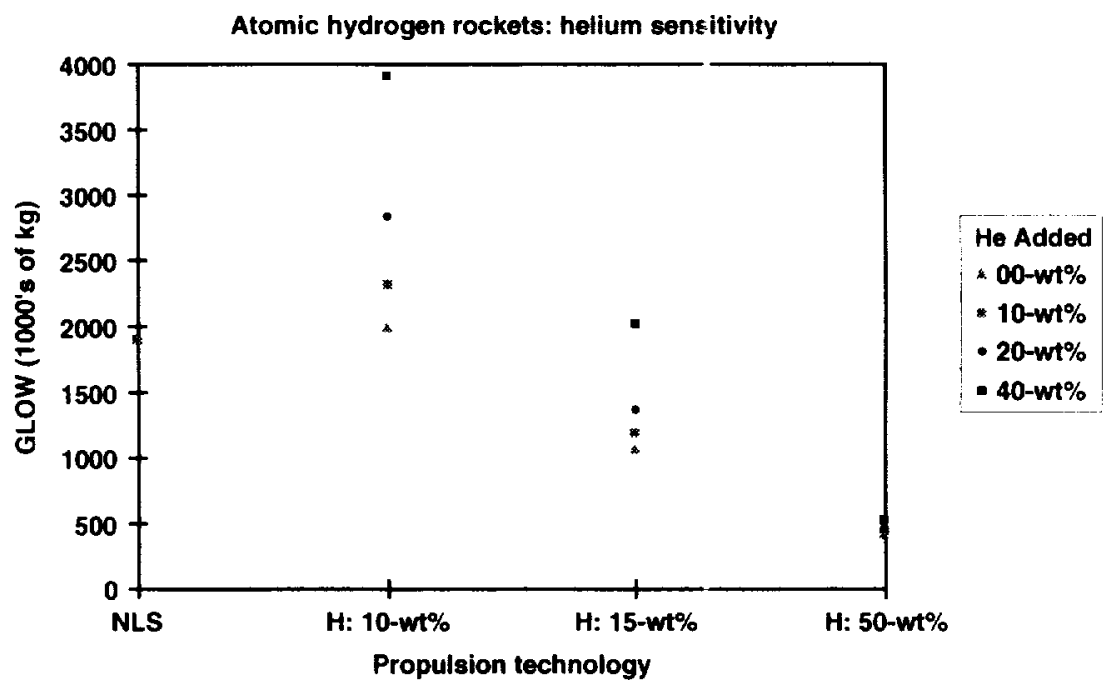

Figure 16.-Atomic hydrogen venicle GLOW. 
Public reporting burden for this collection of information is estimated to average 1 hour per response, including the time for reviewing instructions, searching existing data sources. gathering and maintaining the data needed, and completing and reviewing the collection of information. Send comments regarding this burden estimate or any other aspect of this collection of information, including suggestions for reducing this burden, to Washington Headquarters Services, Directorate for Information Operations and Aeports, 1215 Jefferson Davis Highway. Suite 1204, Arlington, VA 22202-4302, and to the Office of Management and Budget. Paperwork Reduction Project (0704-0188), Washington, DC 20503.

\begin{tabular}{|l|l|l|}
\hline 1. AGENCY USE ONLY (Leave blank) & 2. REPORT DATE & 3. REPORT TYPE AND DATES COVERED
\end{tabular}

\section{TITLE AND SUBTITLE}

November 1998

Technical Memorandum

Launch Vehicle Performance With Solid Particle Feed Systems

for Atomic Propellants

\section{AUTHOR(S)}

Bryan Palaszewski

\section{PERFORMING ORGANIZATION NAME(S) AND ADDRESS(ES)}

8. PERFORMING ORGANIZATION

National Aeronautics and Space Administration

Lewis Research Center

Cleveland, Ohio 44135-3191

WU-260-98-09-00

9. SPONSORING/MONITORING AGENCY NAME(S) AND ADDRESS(ES)

National Aeronautics and Space Administration

Washington, DC 20546-0001

\section{AEPORT NUMBER}

E- 11294

\section{SUPPLEMENTARY NOTES}

Prepared for the 34th Joint Propulsion Conference and Exhibit cosponsored by AIAA, ASME, SAE, and ASEE. Cleveland, Ohio, July 13-15, 1998. Responsible person, Bryan Palaszewski, organization code 5830, (216) 977-7493.

\section{2a. DISTRIBUTION/AVAILABILITY STATEMENT}

12b. DISTRIBUTION CODE

Unclassified - Unlimited

Subject Categories: 15 and 20

Distribution: Nonstandard

This publication is available from the NASA Center for AeroSpace Information. (301) 621-0390.

13. ABSTRACT (Maximum 200 words)

An analysis of launch vehicle Gross Liftoff Weight (GLOW) using high energy density atomic propellants with solid particle feed systems was conducted. The analyses covered several propellant combinations, including atoms of aluminum (Al), boron (B), carbon (C), and hydrogen $(\mathrm{H})$ stored in a solid cryogenic particle, with a cryogenic liquid as the carrier fluid. Several different weight percents $(w t \%)$ for the liquid carrier were investigated and the gross lift off weight (GLOW) of the vehicles using the solid particle feed systems were compared with a conventional $\mathrm{O}_{2} / \mathrm{H}_{2}$ propellant vehicle. The potential benefits and effects of feed systems using solid particles in a liquid cryogenic fluid are discussed.

\section{SUBJECT TERMS}

Atomic hydrogen; Cryogenic fuels; Feed systems; Rocket propulsion; Slurry propellants; Gelled propellants

\begin{tabular}{|c|c|}
\hline $\begin{array}{c}\text { 17. SECURITY CLASSIFICATION } \\
\text { OF REPORT }\end{array}$ & $\begin{array}{c}\text { 18. SECURITY CLASSIFICATION } \\
\text { OF THIS PAGE } \\
\text { Unclassified }\end{array}$ \\
Unclassified \\
\hline
\end{tabular}
19. SECURITY CLASSIFICATION OF ABSTRACT

NSN 7540-01-280-5500

Unclassified

NASA TM-1998-208498

AIAA-98-3736 
